\title{
PHYSICAL PROPERTY MEASUREMENTS ON CESIUM CHLORIDE AND CESIUM CHLORIDE-ALKALI METAL CHLORIDE SYSTEMS
}

$$
\text { by }
$$

\author{
H. T. Fullam \\ Chemical systems Technology section \\ Chemical Technology Department \\ Supported by \\ Atlantic Richfield Hanford Company
}

March 1971

This document is
PUBLICLY RELEASABLE
B Suel
Authorizing Official
Date: $1-31-07$

This report is intended primarily for internal use by the sponsoring organization and Battelle-Northwest.

This report was prepared as an account of work sponsored by the United States Government. Neither sponsored by the United United States Atomic Energy the United States nor the their employees, nor any of Commission, nor any of their employees, nor any of their contractors, subcontractors, or their employees, makes any warranty, express or implied, or assumes any legal liability or responsibility for the accuracy, comproduct or process disclosed, or represents that its use would not infringe privately owned rights. 


\section{DISCLAIMER}

This report was prepared as an account of work sponsored by an agency of the United States Government. Neither the United States Government nor any agency Thereof, nor any of their employees, makes any warranty, express or implied, or assumes any legal liability or responsibility for the accuracy, completeness, or usefulness of any information, apparatus, product, or process disclosed, or represents that its use would not infringe privately owned rights. Reference herein to any specific commercial product, process, or service by trade name, trademark, manufacturer, or otherwise does not necessarily constitute or imply its endorsement, recommendation, or favoring by the United States Government or any agency thereof. The views and opinions of authors expressed herein do not necessarily state or reflect those of the United States Government or any agency thereof. 


\section{DISCLAIMER}

Portions of this document may be illegible in electronic image products. Images are produced from the best available original document. 


\section{I S T R I B U T ION}

BNW

RS Paul

JW Bartlett (2)

JM Batch

LA Bray

RE Burns

HT Fullam (20)

LK Mudge

RE Nightingale

ID Perrigo

CA Rohrmann

HH Van Tuyl

OJ Wick

Technical Files (3)
ARHCO
MD Alford
SJ Beard
GL Borsheim
DA Bruce
HL Caudill
RP Corlew
JB Fecht
WL Godfrey
$\mathrm{RE}$ Isaacson
JR LaRiviere
JD Moore
GC Oberg
IM Richards
PW Smith
RE Smith
HP Show
RE Tomlinson
JH Warren

AEC Richland Operations

OJ Elgert

RK Heusser

EB Jackson

BA Ryan

AEC Division of Isotopes Development

JN Maddox (2)

Oak Ridge National Laboratory

JH Gillette

E Lamb

$\mathrm{KH}$ Iin

AF Rupp 
Page

1. introduction $\ldots \ldots \ldots \ldots \ldots \ldots \ldots \ldots \ldots \ldots \ldots \ldots \ldots$

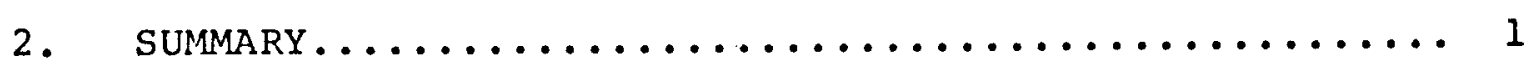

3. CESIUM CHLORIDE PURITY.................... 2

4. PHASE DiAgRAM DETERMinations $\ldots \ldots \ldots \ldots \ldots \ldots \ldots \ldots$

4.1 Melting Point of Cesium Chloride............ 3

$4.2 \mathrm{CsCl}-\mathrm{KCl}$ Binary system................ 4

$4.3 \mathrm{CsCl}-\mathrm{NaCl}$ Binary system................ 4

$4.4 \mathrm{CsCl-KCl-NaCl}$ Ternary system............. 5

5. PHASE TRANSition MEASUREMENTS $\ldots \ldots \ldots \ldots \ldots \ldots \ldots \ldots \ldots$

5.1 Phase Transition of Pure CsC1............. 5

5.2 Phase iransition of the $\mathrm{CsCl}-\mathrm{KCl}$ system....... 6

5.3 Phase Transition of the CsCl-NaCl system....... 8

5.4 Phase Transition of the CsCl-KCl-NaCl system.... 9

6. THERMAL EXPANSION DATA..................... 10

6.1 Cesium Chloride......................... 10

6.2 CsCl-Alkali Chloride systems.............. 11

7. COMPACtion of CESIUM ChLORIDE............... 14

8. ADSORPTION OF MOISTURE.................. 15

9. CAPSUle design COnSiderations $\ldots \ldots \ldots \ldots \ldots \ldots \ldots \ldots$

10 ACKnowledgements........................ 16

11. REFERENCES.......................... 17

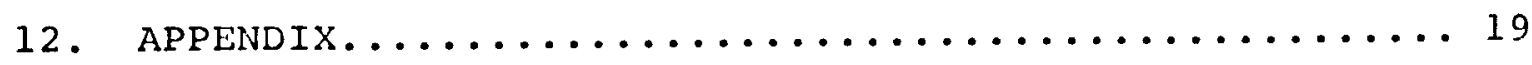

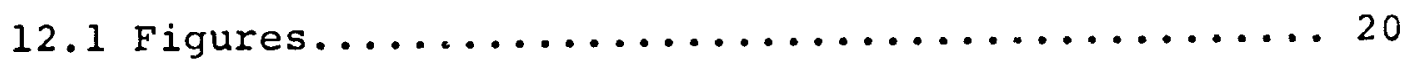




\section{LIST OF TABLES}

I. The Melting Point of Cesium Chloride

II. Phase Transition Data for the system CsCl-KCl-NaCl

III. Thermal Expansion of CsCl-KCl-NaCl Mixtures 


\section{LIST OF FIGURES}

1. Phase Diagram for the system CsCl-KCl

2. Phase Diagram for the system CsCl-KCl (0-10 wto KCl)

3. Phase Diagram for the System CsCl-NaCl

4. Phase Diagram for the system CsCl-NaCl (0-10 wto $\mathrm{NaCl})$

5. Phase Diagram for the system CsCl-KCl-NaCl (Composition in wto )

6. Phase Diagram for the System CsCl-KCl-NaCl (Composition in wto)

7. Thermal Expansion and DTA Curves for Pure Zesium Chloride on Heating

8. The Effect of Heating Rate on CsCl Phase Transition as Determined by Thermal Expansion Measurements

9. Thermal Expansion and Contraction of $\mathrm{CsCl}$ on lieating and cooling

10. Start of Phase Transition for CsCl-KCl Binary as a Function of $\mathrm{KCl}$ Content

11. The Effect of $\mathrm{KCl}$ Content on the Rate of Phase Transition

12. DTA and Thermal Expansion Measurements for Annealed CsCl-10 wto KCl Samples 


\section{LIST OF FIGURES (CONTINUED)}

13. The Effect of NaCl Content on the Phase Transition Temperature of the CsCl-NaCl system

14. Differential Thermal Analysis of a CsCl-3 wtz NaCl Sample

15. Thermal Expansion of a CsCl-10 wto NaCl Sample

16. Thermal Expansion Coefficient for $\mathrm{CsCl}$ as a Function of Temperature

17. Determination of Linear Expansion at the Phase Transition

18. The Effect of Composition on the Average Thermal Expansion Coefficient between $25-300^{\circ} \mathrm{C}$ for the systems $\mathrm{CsCl}-\mathrm{KCl}$ and $\mathrm{CsCl}-\mathrm{NaCl}$

19. Change in Linear Expansion at the Phase Transion with $\mathrm{CsCl}$ Content for the systems $\mathrm{CsCl}-\mathrm{KCl}$ and $\mathrm{CsCl}-$ $\mathrm{NaCl}$

20. Thermal Expansion Curves for Annealed and Unannealed CsCl-10 wto KCl Samples

21. The Effect of Annealing Time on the Linear Expansion of CsCl-NaCl-KCl Samples

22. Compaction of $\mathrm{CsCl}$ By Cold Pressing

23. Cold Pressing of Alkali Chloride Mixtures

24. Adsorption of Water By $\mathrm{CsCl}$ and $\mathrm{Alkali}$ Chloride Mixtures 
1. IITRODUCTION

In the waste management program at Hanford fission product cesium is to be separated from aged wastes and packaged as cesium chloride in small high integrity containers. The physical properties of cesium chloride can affect the process used to load the CsCl into the containers and can influence the design of the containers. In turn, the purity of the cesium chloride can affect its physical properties. It is necessary, therefore, to know the properties of the $\mathrm{CsCl}$ as a function of product purity in order to develop the packaging process. In this study several properties of $\mathrm{CsCl}$ were studied as a function of purity including the solid phase transition, thermal expansion, melting point, and adsorption of water. The compaction of CsCl by step pressing was also evaluated. The results of these studies are summarized in this report.

\section{SUMMARY}

The cesium chloride produced in the Atlantic Richfield Ianford Company (ARICO) waste packaging plant may contain substantial amounts of sodium chloride and potassium chloride. This contamination can affect the physical properties of the CsCl. In this study several properties of CsCl were measured and the effect of $\mathrm{NaCl}$ and $\mathrm{KCl}$ additions on each determined.

The phase diagrams for the systems CsCl-KCl, CsCl-TaCl, and CsCl-KCl-NaCl were determined. The melting point of pure $\mathrm{CsCl}$ was determined to be $645^{\circ} \mathrm{C}$. The CsCl-KCl system shows a minimum melting point of $605^{\circ} \mathrm{C}$ at a $\mathrm{KCl}$ content of 19.2 wt: The CsCl-NaCl system shows an eutectic of $493^{\circ} \mathrm{C}$ at 15.5 wto ivaCl. In the ternary system a minimum melting point of $478{ }^{\circ} \mathrm{C}$ was found at a composition of 68 wto $\mathrm{CsCl}-17$ wt? $\mathrm{KCl}-15$ wto $\mathrm{NaCl}$. 
BNWL-B-74

Pure cesium chloride undergoes a phase transition, on heating, which begins at $475^{\circ} \mathrm{C}$. When $\mathrm{KCl}$ is added the temperature at which the phase transition begins drops sharply. For a CsCl system containing greater than 20 wto $\mathrm{KCl}$ the phase transition initiates below $315^{\circ} \mathrm{C}$. The addition of $\mathrm{NaCl}$ to $\mathrm{CsCl}$ causes only a slight drop in the phase transition temperature. In the ternary system $\mathrm{CsCl}-\mathrm{KCl}-\mathrm{NaCl}$ the phase transition temperature decreases sharply as the $\mathrm{CsCl}$ content is decreased.

Additions of $\mathrm{NaCl}$ and/or $\mathrm{KCl}$ to $\mathrm{CsCl}$ causes the thermal expansion coefficient (below the phase transition) of the system to decrease. The linear expansion due to the phase transition is almost directly proportional to the $\mathrm{CsCl}$ in the system.

The presence of impurities can have a pronounced effect on the properties of $\mathrm{CsCl}$; and these effects must be considered when designing the container which is to be used for packaging the CsCl.

\section{CESIUM CHLORIDE PURITY}

It is anticipated that the cesium chloride prepared in the Waste Packaging Plant may contain as much as 10 wto impurities. It is further anticipated that sodium chloride and potassium chloride will be the major impurities with lesser amounts of other materials present (i.e. rubidium chloride and corrosion products). Studies have been made to measure several of the physical properties of $\mathrm{CsCl}$ and to determine the effect of sodium chloride and potassium chloride additions on some of these properties. The results of the studies are presented in the following sections. 


\section{BNWL-B -74}

\section{PHASE DIAGRAM DETERMINATIONS}

\subsection{Melting Point of Cesium Chloride}

Reported values for the melting point of pure $\mathrm{CsCl}$ vary over a wide range as shown by the data presented in Table I.

\section{TABLE I. The Melting Point of Cesium Chloride}

$\begin{array}{cccc}\text { Value, }{ }^{\circ} \mathrm{C} & \text { Reference } & \frac{\text { Value, }{ }^{\circ} \mathrm{C}}{645} & \frac{\text { Reference }}{629} \\ 630 & 1 & 646 & 6 \\ 638 & 2 & 647 & 7 \\ 640 & 3 & 648 & 8 \\ 643 & 4 & 649 & 10\end{array}$

An average value for the melting point, based on 18 reputable literature values, appears to be about $645^{\circ} \mathrm{C}$. In this work the melting point of $\mathrm{CsCl}$ was determined in two ways: by differential thermal analysis and by the thermal arrest method. A DuPont Model 900 Differential Thermal Analyzer was used for the DTA studies. The thermal arrest measurements were obtained in the standard fashion using porcelain or quartz crucibles, calibrated chromel-alumel thermocouples, and a Moseley X-Y recorder. The cesium chloride used in the work was obtained from Varlacoid Chemical Company and had a reported purity of $99.9+8$. Emission and spark source mass spectroscopy verified the purity value. 
Good agreement was obtained between the two methods. A melting point for $\mathrm{CsCl}$ of $644 \pm 3{ }^{\circ} \mathrm{C}$ was obtained by differential thermal analysis (DTA) based on twenty measurements. The thermal arrest method gave a melting point of $646 \pm 2{ }^{\circ} \mathrm{C}$ based on twelve measurements. Based on the two methods, the melting point of $\mathrm{CsCl}$ is taken as $645^{\circ} \mathrm{C}$.

\subsection{CsCl-KCl Binary System}

The phase diagram for the binary system $\mathrm{CsCl-KCl}$ was studied over the entire composition range. The two salts form a solid solution having a minimum melting point. Thermal arrest and DTA measurements were used to determine the various points in the diagram. The phase diagram obtained is shown in Figure 1. The system has a minimum melting point of $605^{\circ} \mathrm{C}$ at a $\mathrm{KCl}$ content of $19.2 \mathrm{wt} \%$. The area of the diagram of particular interest (0-10 wt: $\mathrm{KCl})$ is shown in Figure 2. The diagram differs from those reported by Dombrovskaya ${ }^{(11)}$ and $z$ hemchuzhnui ${ }^{(7)}$ in that the minimum melting point obtained in this study is $10-25^{\circ} \mathrm{C}$ lower than those previously reported. Our value does agree quite closely with the value of $606^{\circ} \mathrm{C}$ reported by Ilyasov (12) who studied the CsCl-KCl-NaCl ternary.

\subsection{CsCl-NaCl Binary System}

The phase diagram for the binary system CsCl-NaCl was also determined over the entire composition range using thermal arrest, DTA, and x-ray analysis. The results obtained are presented in Figure 3. The system has a eutectic at 15.5 wto NaCl with a melting point of $493^{\circ} \mathrm{C}$. The two salts do not form a solid solution, and below $493^{\circ} \mathrm{C}$ the system consists of two solid phases. However, there does appear to be a slight solubility of $\mathrm{NaCl}$ in solid $\mathrm{CsCl}$. 
The phase diagram obtained is similar to that reported by Samuseva ${ }^{(9)}$ except in the 20-75\% llaCl portion of the diagram where the liquidus line varies significantly from that reported by Samuseva. Samuseva's data are shown in Figure 3 by the dashed line. The 0-10 wto laCl portion of the diagram is shown in Figure 4 .

\subsection{CsCl-KCl-NaCl Ternary System}

The phase diagram for the ternary system CsCl-KCl-ivaCl was studied over the entire composition range with emphasis on that area of the diagram containing $\geq 90 \mathrm{wt}: \mathrm{CsCl}$. The diagram obtained is presented in Figures 5 and 6 . It is very similar to that reported by Ilyasov (12) except in the low CsCl portion of the diagram. In this study it was found that the ternary has a minimum melting point of $478 \pm 3^{\circ} \mathrm{C}$ at a composition of 68 wto $\mathrm{CsCl}$ - $17 \mathrm{wt} \% \mathrm{KCl}$ - 15 wto NaCl. Ilyasov reports a minimum melting point of $480^{\circ} \mathrm{C}$ at $68.1 \mathrm{wt} \mathrm{CsCl}-16.3$ wto $\mathrm{KCl}$ 15.6 wto $\mathrm{NaCl}$. The only major difference in the two diagrams is the minimum melting point for the NaCl-KCl binary. Ilyasov reported a temperature of $658^{\circ} \mathrm{C}$. We obtained a value of 646 $\pm 4{ }^{\circ} \mathrm{C}$ (which agrees with the value of $645 \pm 2{ }^{\circ} \mathrm{C}$ reported by Coleman and Lacy (13), The difference in the two values changes the position of the isotherms slightly in the low CsCl area of the phase diagram.

\section{PHASE TRANSITION MEASUREMENTS}

\subsection{Phase Transition of Cesium Chloride}

Pure cesium chloride undergoes a phase transition on heating from the low temperature $\mathrm{CsCl}$ structure (cubic) to a high temperature sodium chloride structure (face-centered cubic). 
The phase transition has been reported to occur at $469^{\circ} \mathrm{C}$.

In this study the phase transition temperature was determined by differential thermal analysis and thermal expansion measurements using the DuPont Model 900 Differential Thermal Analyzer and Thermomechanical Analyzer accessory. Typical DTA and thermal expansion data for $99.9+\frac{8}{\mathrm{CsCl}}$ are shown in Figure 7. DTA data gave a value of $474 \pm 3{ }^{\circ} \mathrm{C}$ for the temperature at which the phase transition starts. Thermal expansion measurements gave a value of $475 \pm 2{ }^{\circ} \mathrm{C}$. The phase transition, on heating, is not instantaneous, and when the CsCl sample is heated at a finite rate the phase transition takes place over a substantial temperature range. Figure 8 presents several thermal expansion curves for a CsCl sample heated at different rates and shows that the faster the heating rate the greater the temperature range over which the transition occurs.

When the high temperature form of $\mathrm{CsCl}$ is cooled the reversion to the low temperature form occurs at approximately the same rate as on heating. Figure 9 shows a typical expansion and contraction curve for pure $\mathrm{CsCl}$.

\subsection{Phase Transition of the CsCl-KCl System}

When $\mathrm{KCl}$ is added to $\mathrm{CsCl}$ the temperature at which the phase transition starts is decreased greatly. The rate at which the phase transition occurs on heating is also decreased. More important, however, is the fact that the rate of phase transition on cooling is decreased very significantly so that with finite cooling rates $\left(>0.5^{\circ} \mathrm{C} / \mathrm{min}\right)$ very little reversion occurs on cooling a CsCl-KCl sample. It is necessary to anneal the sample 
at 250-300 ${ }^{\circ} \mathrm{C}$ for substantial periods of time (>4 hours) to insure complete reversion of the $\mathrm{CsCl}$ to the low temperature form. X-ray diffraction patterns obtained at room temperature with unannealed samples, containing $1-5$ wto $\mathrm{kCl}$, showed a mixture of the low temperature and high temperature forms of $\mathrm{CsCl}$ was present.

Figure 10 shows how the temperature at which the phase transition starts decreases as the $\mathrm{KCl}$ content increases. Fair agreement was achieved between DTA and thermal expansion measurements. The phase transition was detected for samples containing as much as $90 \mathrm{wt} \% \mathrm{KCl}$. However, the temperature at which the transition starts is poorly defined for samples containing over $50 \mathrm{wt} / \mathrm{kCl}$. Additional work is needed to determine accurately the phase transition temperatures for samples high in $\mathrm{KCl}$.

The rate at which the phase transition occurs, on heating, depends on the $\mathrm{KCl}$ content. Figure 11 shows the thermal expansion curves for CsCl-KCl samples of various compositions, all of which were heated at the same rate. It is aifficult to obtain a precise measure of the rate of transition. However, from the curves presented in Figure 11 it is readily apparent that the temperature range over which the transition occurs increases as the $\mathrm{KCl}$ content of the binary increases.

When a CsCl-KCl sample is cooled, the reversion to the low temperature form is inhibited by the ICl. For example, Figure 12 shows DTA and thermal expansion-contraction plots for annealed samples of CsCl-10 wt: $\mathrm{KCl}$. The phase transition on heating is readily apparent on both the DTA and expansion 
curves. Upon cooling, however, it is impossible to detect the phase transition by DTA, and only a slight indication of the transition is observed in the thermal contraction curve. If a $\mathrm{CsCl}-\mathrm{KCl}$ sample is reheated after rapid cooling $\left(>10^{\circ} \mathrm{C} / \mathrm{min}\right)$ it is impossible to detect a phase transition by DTA, although a slight transition can be detected by the thermal expansion procedure.

\subsection{Phase Transition of the CsCl-NaCl system}

It has been reported that in the $\mathrm{CsCl}-\mathrm{NaCl}$ system two solid phases form below the eutectic temperature of $493^{\circ} \mathrm{C}$ with no solid solution. (9) If this is true then the phase transition temperature for $\mathrm{CsCl}$ should be unaffected by the addition of NaCl. In this study, however, it was found that the temperature at which the transition starts decreased slightly with the addition of $\mathrm{NaCl}$ (see Figure 13). This indicates there is probably a slight solubility of $\mathrm{NaCl}$ in solid $\mathrm{CsCl}$.

It was impossible to obtain good thermal contraction curves for the CsCl-NaCl system because of the low eutectic temperature $\left(493^{\circ} \mathrm{C}\right)$. In all cases the sample began to melt before the phase transition was complete on heating. DTA data showed that the phase transition occurred on cooling regardless of the cooling rate. However, the temperature at which the phase transition started was substantialiy lower than the temperature at which the transition began on heating. Figure 14 shows the results obtained with a $\mathrm{CsCl}-3$ wto $\mathrm{NaCl}$ sample. Other CsCl$\mathrm{NaCl}$ compositions showed a similar lowering of the transition temperatures on coolings. However, it was impossible to correlate the temperature lowering with composition. If the thermal expansion runs were stopped before the phase transition was 
complete (and before the eutectic temperature was reached) the sample could be cooled and a thermal contraction curve obtained. Figure 15 shows such a curve for a CsCl-10 wto vaCl sample. It is interesting to note that even though the phase transition was incomplete when cooling was started the phase reversion did not begin until the temperature had dropped approximately $60^{\circ} \mathrm{C}$. This temperature was at least $25^{\circ} \mathrm{C}$ below where the phase transition had started on heating.

\subsection{Phase Transition of the CsCl-KCl-NaCl System}

The CsCl-KCl-NaCl system is quite complex. The phase transition was detected on heating for all compositions containing $\geq 10 \mathrm{wto} \mathrm{CsCl}$. As with the CsCl-KCl system, however, samples must be annealed to assure complete reversion to the low temperature form on cooling. The temperature at which the phase transition starts, on heating, depends on the composition but the exact relationship is very complex. In the ternary system, $\mathrm{NaCl}$ acts almost like $\mathrm{KCl}$ in its effect on the phase transition temperature. This can be seen by referring to the data presented in Table II. For the ternary system, it is best to assume that the $\mathrm{NaCl}$ is $\mathrm{KCl}$ and that the phase transition will occur as shown in Figure 10. 
TABLE II. Phase Transition Data For CsCl-KCl-NaCl system

\begin{tabular}{|c|c|c|c|}
\hline \multicolumn{3}{|c|}{ Composition, wt: } & \multirow{2}{*}{$\begin{array}{l}\text { Start of Phase } \\
\text { Transition, }{ }^{\circ} \mathrm{C}\end{array}$} \\
\hline $\mathrm{CsCl}$ & $\underline{\mathrm{KCl}}$ & $\mathrm{NaCl}$ & \\
\hline 95 & 5 & 0 & 340 \\
\hline 95 & 4 & 1 & 343 \\
\hline 95 & 3 & 2 & 340 \\
\hline 95 & 2 & 3 & 338 \\
\hline 95 & 1 & 4 & 342 \\
\hline 95 & 0 & 5 & 465 \\
\hline 90 & 10 & 0 & 320 \\
\hline 90 & 9 & 1 & 321 \\
\hline 90 & 7 & 3 & 325 \\
\hline 90 & 5 & 5 & 323 \\
\hline 90 & 3 & 7 & 324 \\
\hline 90 & 1 & 9 & 320 \\
\hline 90 & 0 & 10 & 467 \\
\hline
\end{tabular}

6. THERMAL EXPANSION DATA

\subsection{Cesium Chloride}

The thermal expansion of pure CsCl was determined from $25{ }^{\circ} \mathrm{C}$ through the phase transition (up to $540^{\circ} \mathrm{C}$ ). Expansion up to the phase transition temperature is almost linear with temperature. Figure 16 gives the value of the thermal expansion coefficient, $\alpha$, as a function of temperature for CsCl. For this work, the thermal expansion coefficient will nornally be reported as an average value for the temperature range $25-300{ }^{\circ} \mathrm{C}$. 
A value of $300^{\circ} \mathrm{C}$ was selected as the upper limit because it is just below the minimum temperature at which the phase transition starts in the CsCl-KCl and CsCl-KCl-NaCl systems.

For pure $\mathrm{CsCl}, \alpha_{25-300{ }^{\circ} \mathrm{C}}$ was determined to be $55.5 \times 10^{-6} /{ }^{\circ} \mathrm{C}$ (based on ten determinations). This is in exact agreement with the value of $\alpha_{20-320{ }^{\circ} \mathrm{C}}=55.5 \times 10^{-6} /{ }^{\circ} \mathrm{C}$ reported by whittemore.

For the high temperature form of $\mathrm{CsCl}$ the thermal expansion coefficient between 500 and $540{ }^{\circ} \mathrm{C}$ was determined to be $\alpha_{500-540}{ }^{\circ} \mathrm{C}$ $=42.5 \times 10^{-6} /{ }^{\circ} \mathrm{C}$, which was slightly lower than the value of $\alpha_{570-5900^{\circ} \mathrm{C}}=51 \times 10^{-6} /{ }^{\circ} \mathrm{C}$ reported by Christian and Lynch.

At the phase transition, the linear expansion was calculated at the mid-point of the temperature range over which the transition occurs (see Figure 17). For pure CsCl the linear expansion at the phase transition was determined to be $5.4 \%$. Since the two $\mathrm{CsCl}$ structures are cubic and isotropic, the volumetric expansion at the phase transition is the cube of the linear expansion. This gives a value of $17.1 \%$ for the volumetric expansion of $\mathrm{CsCl}$ due to the phase transition. This compares with a value of $16 \%$ reported by Menary, et.al. (14)

\subsection{CsCl-Alkali Metal Chloride Systems}

For the $\mathrm{CsCl}-\mathrm{KCl}$ and $\mathrm{CsCl}-\mathrm{NaCl}$ systems the value of $\alpha_{25-300}{ }^{\circ} \mathrm{C}$ decreases as the $\mathrm{CsCl}$ content of the system decreases. Figure 18 shows the relationship between $\alpha_{25-300}{ }^{\circ} \mathrm{C}$ and composition for the two systems. For pure $\mathrm{KCl}$ and pure $\mathrm{NaCl}$, values for $\alpha_{25-300{ }^{\circ} \mathrm{C}}$ of $41.6 \times 10^{-6} /{ }^{\circ} \mathrm{C}$ and $43.0 \times 10^{-6} /{ }^{\circ} \mathrm{C}$ were obtained. These compare with values of $41.7 \times 10^{-6} /{ }^{\circ} \mathrm{C}$ and $45.6 \times 10^{-6} /{ }^{\circ} \mathrm{C}$ reported in the literature for $\alpha_{20-320}{ }^{\circ} \mathrm{C}$. 
The linear expansion at the phase transition for both the CsCl-NaCl and $\mathrm{CsCl}-\mathrm{KCl}$ systems is almost directly proportional to the CsCl content of the system. Figure 19 shows how the linear expansion varies with composition for both systems.

All the thermal expansion data presented for the CsCl$\mathrm{KCl}$ systems were obtained with samples which were melt cast and then fully annealed to insure complete reversion to the low temperature form. If the samples were not annealed it was impossible to obtain reproducible thermal expansion data. For example, when an unannealed CsCl-10 wto $\mathrm{KCl}$ sample is heated, some high temperature phase material is initially present. When the temperature reached 200-300 ${ }^{\circ} \mathrm{C}$ the high temperature material partially reverts to the low temperature form. This results in an actual decrease in sample length (see Figure 20) even though the sample temperature is increasing. Such behavior makes it impossible to accurately determine the thermal expansion between 25 and $300^{\circ} \mathrm{C}$ and at the phase transition without annealing. It was normally necessary to anneal the samples for several hours at $250-300^{\circ} \mathrm{C}$ to insure complete reversion to the low temperature form.

With the CsCl-KCl-NaCl system it is also necessary to anneal the samples to obtain reliable thermal expansion data. Figure 21 shows how the thermal expansion from $25-400{ }^{\circ} \mathrm{C}$ for ternary samples varies with the annealing time (the expansion data presented in Figure 21 include the expansion due to the phase transitions). The data show that an annealing time of at least 4 hours at $275^{\circ} \mathrm{C}$ is required to obtain complete reversion.

Linear expansion values between $25-300^{\circ} \mathrm{C}$ for the various ternary compositions fall between those obtained for the two binary compositions of the same $\mathrm{CsCl}$ content (see Table III). 
TABLE III. Thermal Expansion of CsCl-KCl-NaCl Mixtures

\begin{tabular}{|c|c|c|c|}
\hline \multicolumn{3}{|c|}{ Composition, wt: } & \multirow{2}{*}{$\alpha_{25-300}{ }^{\circ} \mathrm{C}$} \\
\hline $\mathrm{CsCl}$ & $\mathrm{KCl}$ & $\mathrm{NaCl}$ & \\
\hline 90 & 10 & 0 & $48.0 \times 10^{-6}$ \\
\hline 90 & 0 & 10 & $49.4 \times 10^{-6}$ \\
\hline 90 & 5 & 5 & $48.5 \times 10^{-6}$ \\
\hline 70 & 30 & 0 & $45.0 \times 10^{-6}$ \\
\hline 70 & 0 & 30 & $46.3 \times 10^{-6}$ \\
\hline 70 & 10 & 20 & $45.7 \times 10^{-6}$ \\
\hline 70 & 15 & 15 & $45.5 \times 10^{-6}$ \\
\hline 70 & 20 & 10 & $45.4 \times 10^{-6}$ \\
\hline
\end{tabular}

In those cases where it is critical to know the maximum thermal expansion which may occur, it is best to assume all of the $\mathrm{KCl}$ and $\mathrm{NaCl}$ in the ternary is $\mathrm{NaCl}$ and take the thermal expansion value from the CsCl-NaCl curve in Figure 18.

At the phase transition, the expansion which occurs with the ternary system is dependent on the csCl content, and the value can be taken from the binary data presented in Figure 19. For example, a sample containing 50 wto CsCl-25 wt: NaCl25 wto $\mathrm{KCl}$ will have approximately the same linear expansion at the phase transition as one containing 50 wt: CsCl-50 wto $\mathrm{KCl}$ or 50 wto $\mathrm{CsCl}-50$ wto $\mathrm{NaCl}$. 


\section{COMPACTION OF CESIUM CHLORIDE}

High purity $\left(99.9+\frac{\circ}{6}\right)$ cesium chloride is readily compacted to high densities by cold pressing. Pellets of CsCl were pressed to $>99 \%$ of theoretical density at pressures as low as 38 tons (TSI) per square inch. The theoretical density of CsCl at $25^{\circ} \mathrm{C}$ was taken as $3.999 \mathrm{~g} / \mathrm{cm}^{3}$. (17) cesium chloride powder prepared by the packaging plant flowsheet and which contained 3.5 wt? impurities compacted almost as readily as pure CsCl. Figure 22 shows the densities obtained when $\mathrm{CsCl}$ prepared by the flowsheet was cold pressed into pellets at various pressures. The densities were calculated from the physical dimension of the pellets.

When $\mathrm{KCl}$ or $\mathrm{NaCl}$ is added to pure $\mathrm{CsCl}$ and the mixture melted, solidified, and crushed the resultant powder is more difficult to press than pure $\mathrm{CsCl}$. Figure 23 shows compaction data for various CsCl-KCl, $\mathrm{CsCl}-\mathrm{NaCl}$ and $\mathrm{CsCl}-\mathrm{KCl}-\mathrm{NaCl}$ mixtures. The theoretical densities of the mixtures were taken as the arithmetic average of the individual components:

Theoretical Density = (binary)

Theoretical Density = (ternary)

$\frac{100}{\text { wensity } A}+\frac{\text { wt: } B}{\text { Density of } B}$

100

$\frac{\text { wt\% } A}{\text { Density of } A}+\frac{\text { wt\% } B}{\text { Density of } B}+\frac{\text { wt\% } C}{\text { Density of } C}$


8. ADSORPTION OF MOISTURE

When $\operatorname{CSCl}$ is exposed to atmospheric moisture it will adsorb the moisture at a relatively slow rate. Mixtures of $\mathrm{CsCl}$ and $\mathrm{KCl}$ and/or $\mathrm{NaCl}$ will adsorb atmospheric moisture at a more rapid rate. To make the measurements, samples of $\mathrm{CsCl}$ plus $\mathrm{KCl}$ and/or NaCl were melted, solidified, and crushed to -100 mesh. Samples of each powder were placed in open beakers and exposed to the atmosphere. The weight change, indicating pickup of water, was followed as a function of time. The results obtained are shown in Figure 24. Cesium chloride samples, prepared in the same fashion as the CsCl-NaCl-KCl mixtures, were also run as a standard for comparative purposes. The results show that the lower the CsCl content of the mixture the more rapid the adsorption of moisture.

\section{CAPSULE DESIGN CONSIDERATIONS}

The CsCl prepared in the packaging plant will be stored in small high integrity containers. Without external cooling the centerline of the container may reach a temperature as high as $400^{\circ} \mathrm{C}$. Under these conditions, impurities in the $\mathrm{CsCl}$ can have a significant effect on the condition of the chloride in the container. For example, if the $\mathrm{CsCl}$ in the container is at a temperature above $350^{\circ} \mathrm{C}$, and if the $\mathrm{CsCl}$ contains greater than 3 wt: $\mathrm{KCl}$, then the $\mathrm{CsCl}$ will be in the high temperature form. Therefore, the capsule must be designed to allow for expansion of the $\mathrm{CsCl}$ to the high temperature form. If melt casting is used to fill the $\mathrm{CsCl}$ containers, thermal expansion would not be a problem. If the $\mathrm{CsCl}$ contains both $\mathrm{KCl}$ and $\mathrm{IJaCl}$ then a molten phase will be present if the temperature of the salt exceeds $478{ }^{\circ} \mathrm{C}$. This can have an effect on the compatibility of the salt with the container metal. In designing the $\mathrm{CsCl}$ 
container it is necessary, therefore, to consider all of the effects which impurities will have on the properties of the CsCl.

\section{ACKNOWLEDGEMENTS}

The author is indebted to $\mathrm{Mr}$. C. I. Nelson who performed much of the experimental work covered in this report. 


\section{REFERENCES}

1. H. Keitel. Neues Jahrb. Mineral Geol, , A52, p. 420. 1955.

2. E. P. Dergunov, Dokl. Akad Nauk SSSR, 64 (4), p. 519.1949.

3. A. Bernman and G. N. Maslennikova, Russian J. Inorg. Chem.' p. 714. 1962. (Eng. Trans.).

4. In-Chzhu Sun and I.S. Morozov, Zhur. Neorg. Khim., 3, p. 916. 1958.

5. B. F. Markov, Zhur. Obshchei Khim., 25, p. 2042 . 1955 .

6. V. V. Safonov, et.al., Pussian J. Inorg. Chem., P. 1022 . 1962. (Eng. Trans).

7. S. Zhemchuzhnui and F. Rambach, Z. Anorg. Chem., 65, p. 421. 1910.

8. B. F. Markov, et.al., Ukrain, Khim. Zhur., 22, p. 290. 1956.

9. R. G. Samuseva and V. E. Plyushchev, Russian J. Inorg. Chem., p. 1093. 1960. (Eng. Trans).

10. B. G. Korshunov, et.al., Russian J. Inorg. Chem., p. 774. 1964. (Eng. Trans.)

11. O. S. Dombrovskaya, zh. Obshch. Khim., 3, p. 1019. 1933. 
12. I. I. Ilyasov and A. G. Bergman, Russian J. Inorg. Chem., p. 356 1962. (Eng. Trans.)

13. Coleman and Lacy. Mat. Res. Bul1, 2, p. 935.1967.

14. J. W. Menary, A. R. Ubbelohde and I. Woodward, Proc. P.oy. Soc. (London), A208, p. 159. 1951.

15. D. Whittemore, Ceramic Bulletin, 41, p. 513. 1962.

16. J. M. Christian and D. W. Lynch, J. Chem. Phys., 40, p. 248,1964 .

17. J. W. Johnson, P. A. Argon, and M. A. Bredig, J.Am. Chem. Soc., 77, pp. 2734-7. 1955. 
12. APPENDIX

$-19-$ 


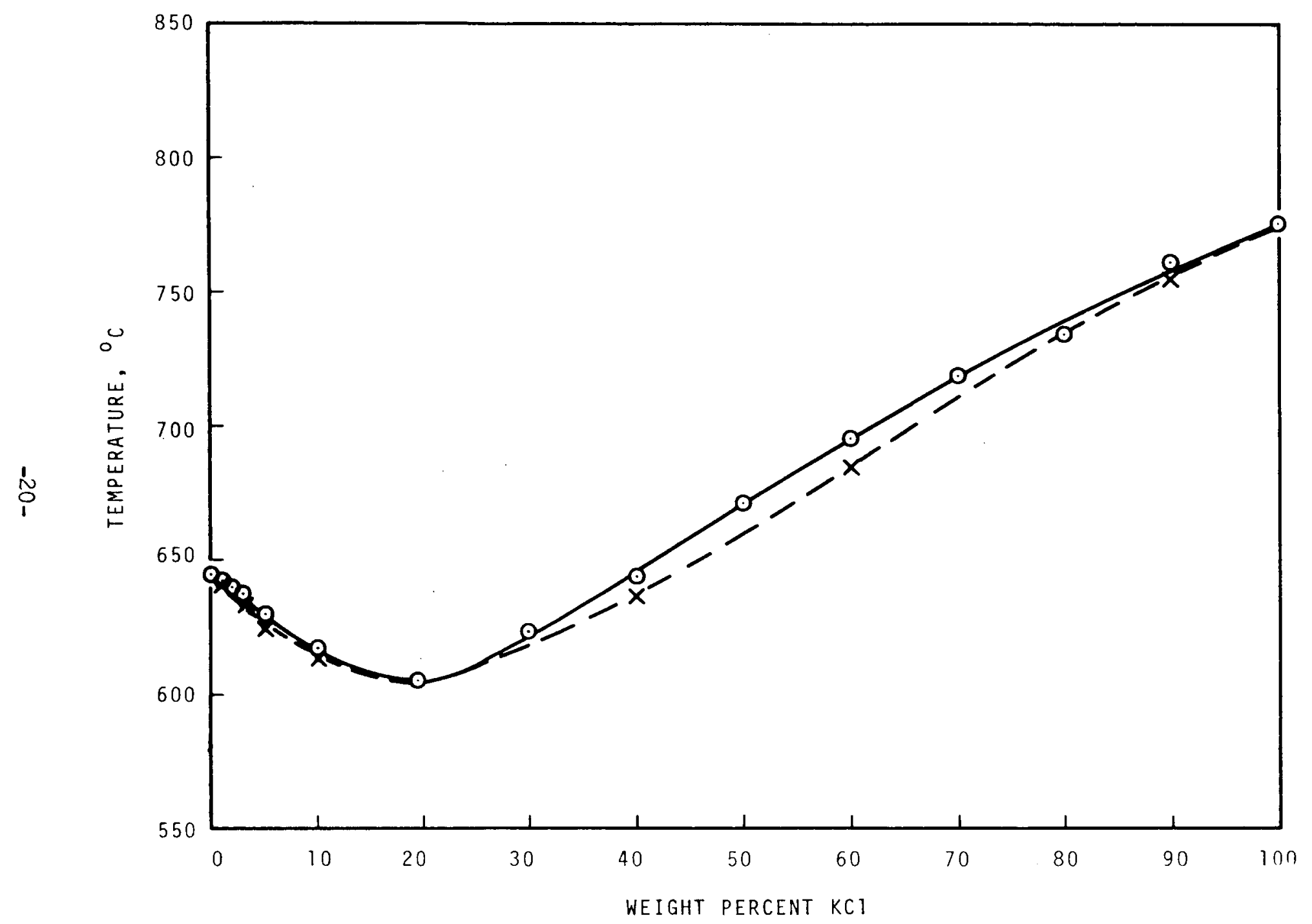

FIGURE 1 PHASE DIAGRAM FOR THE SYSTEM CSCI-KC1 


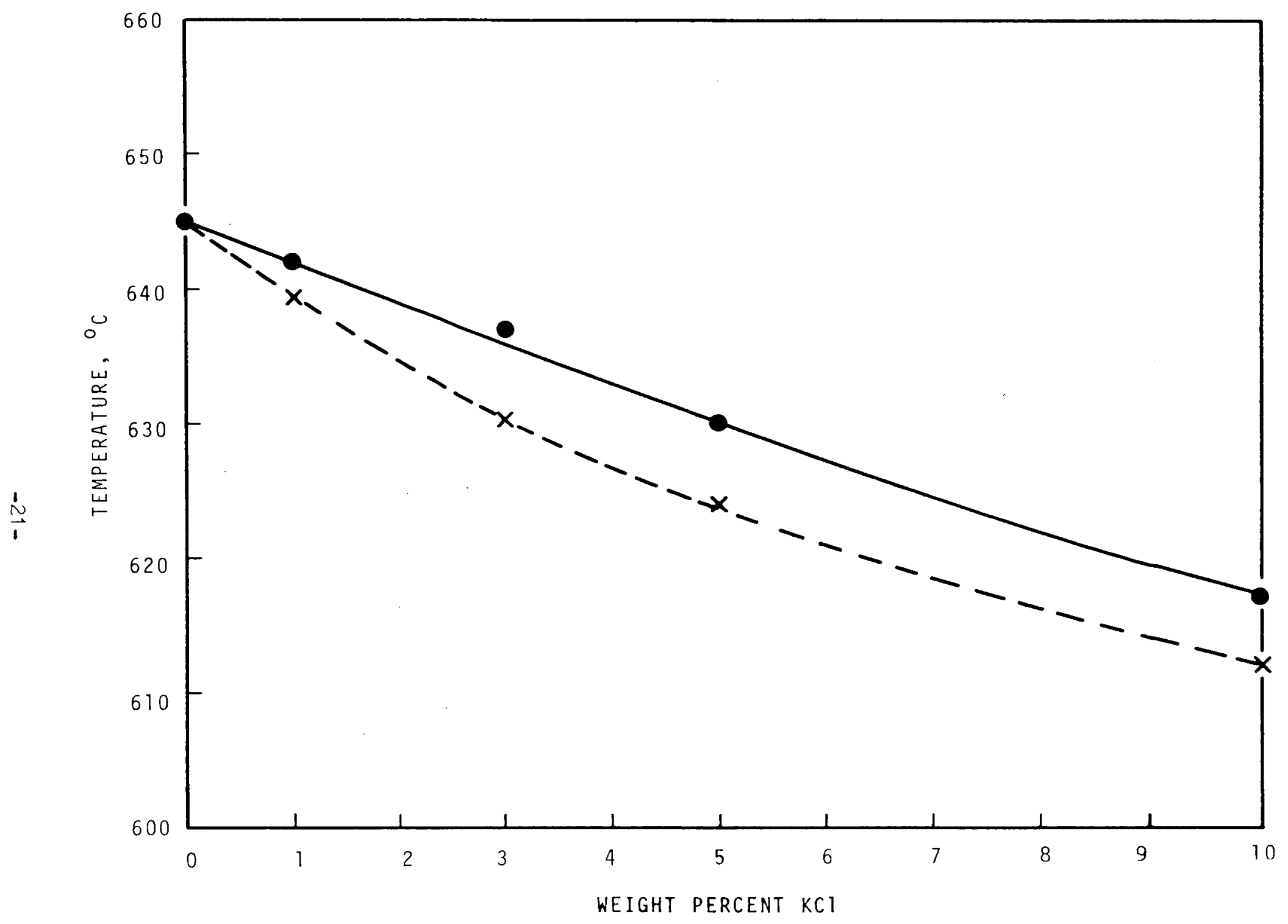

FIGURE 2 PHASE DIAGRAM FOR THE SYSTEM CsC1-KCl (0-10 wt\% KCl) 


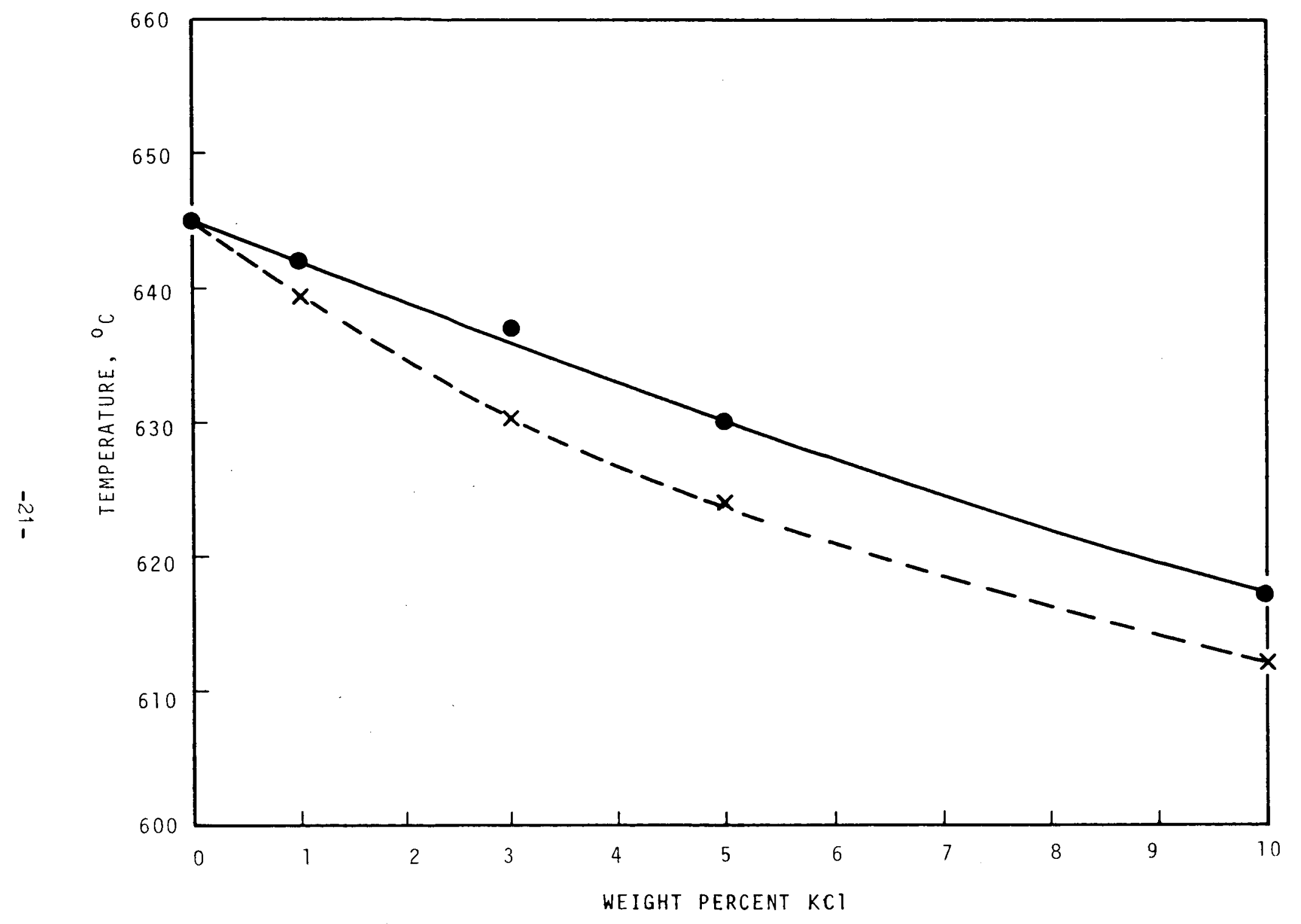

FIGURE 2 PHASE DIAGRAM FOR THE SYSTEM CsC1-KC1 (0-10 wt\% KCl) 


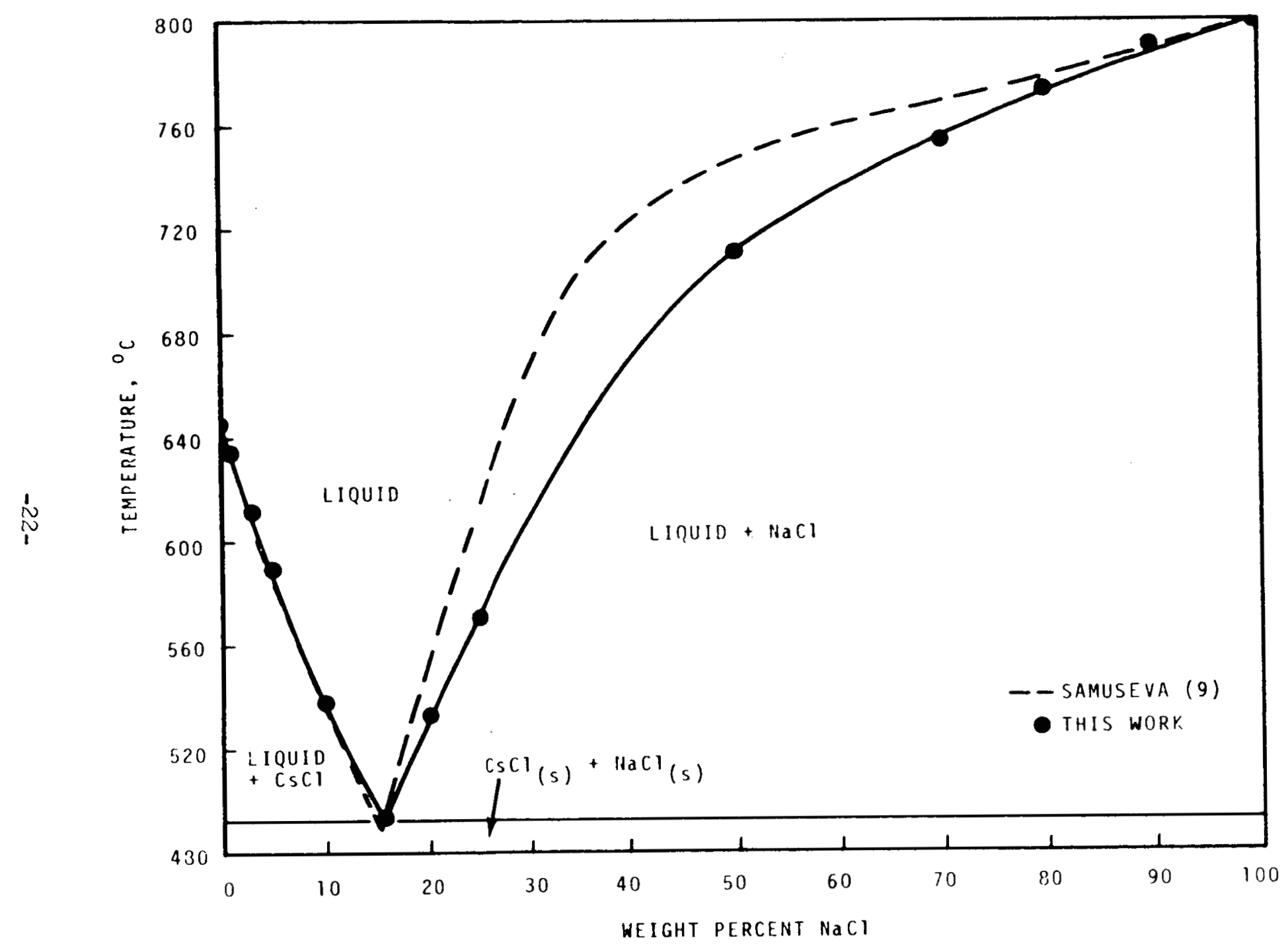

FIGURE 3 PHASE DIAGRAM FOR THE SYSTEM CSCI-NaC1 


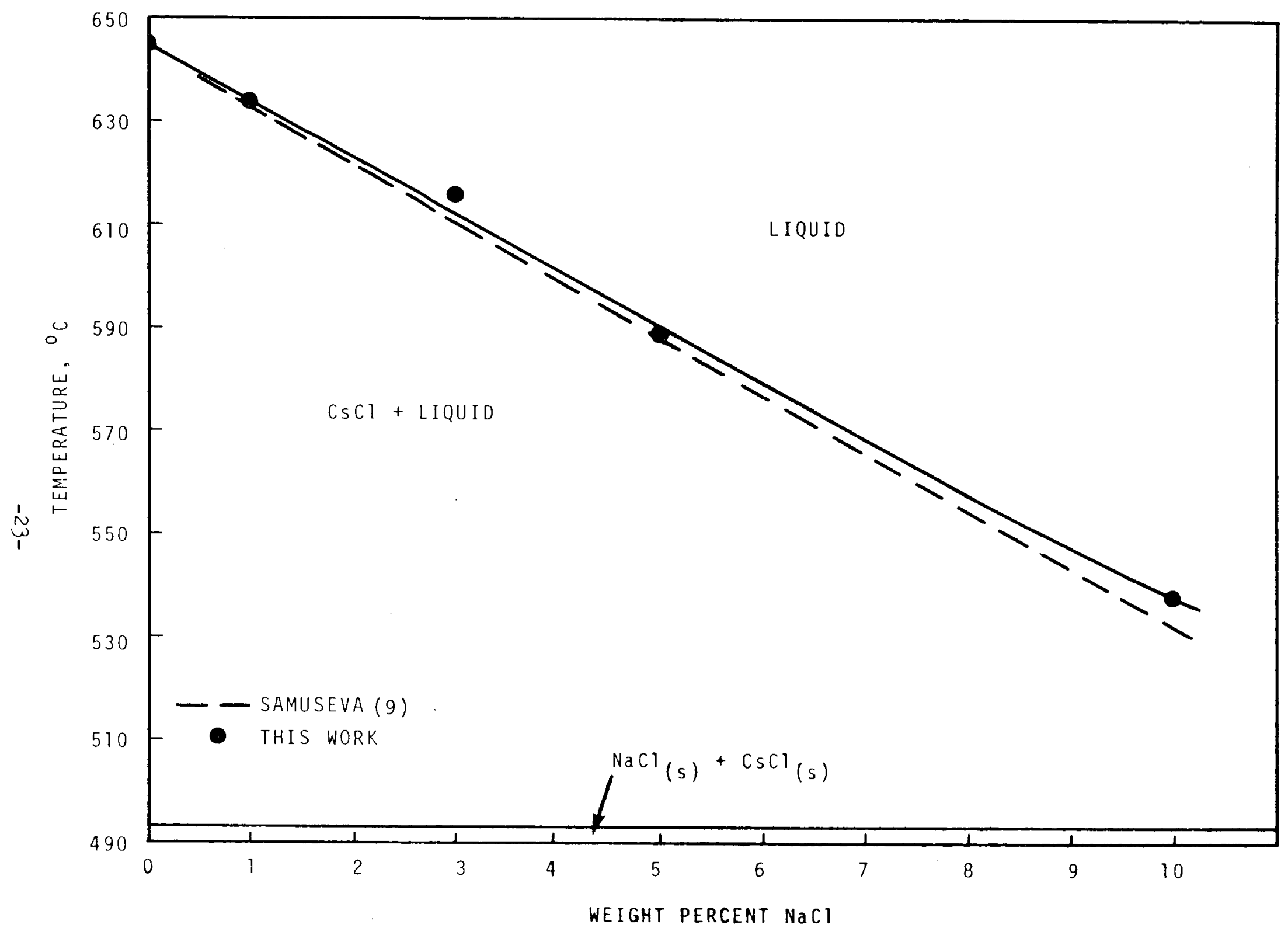

FIGURE 4 PHASE DIAGRAM FOR THE SYSTEM CsC1-NaC1 (0-10 wt\% NaC1) 


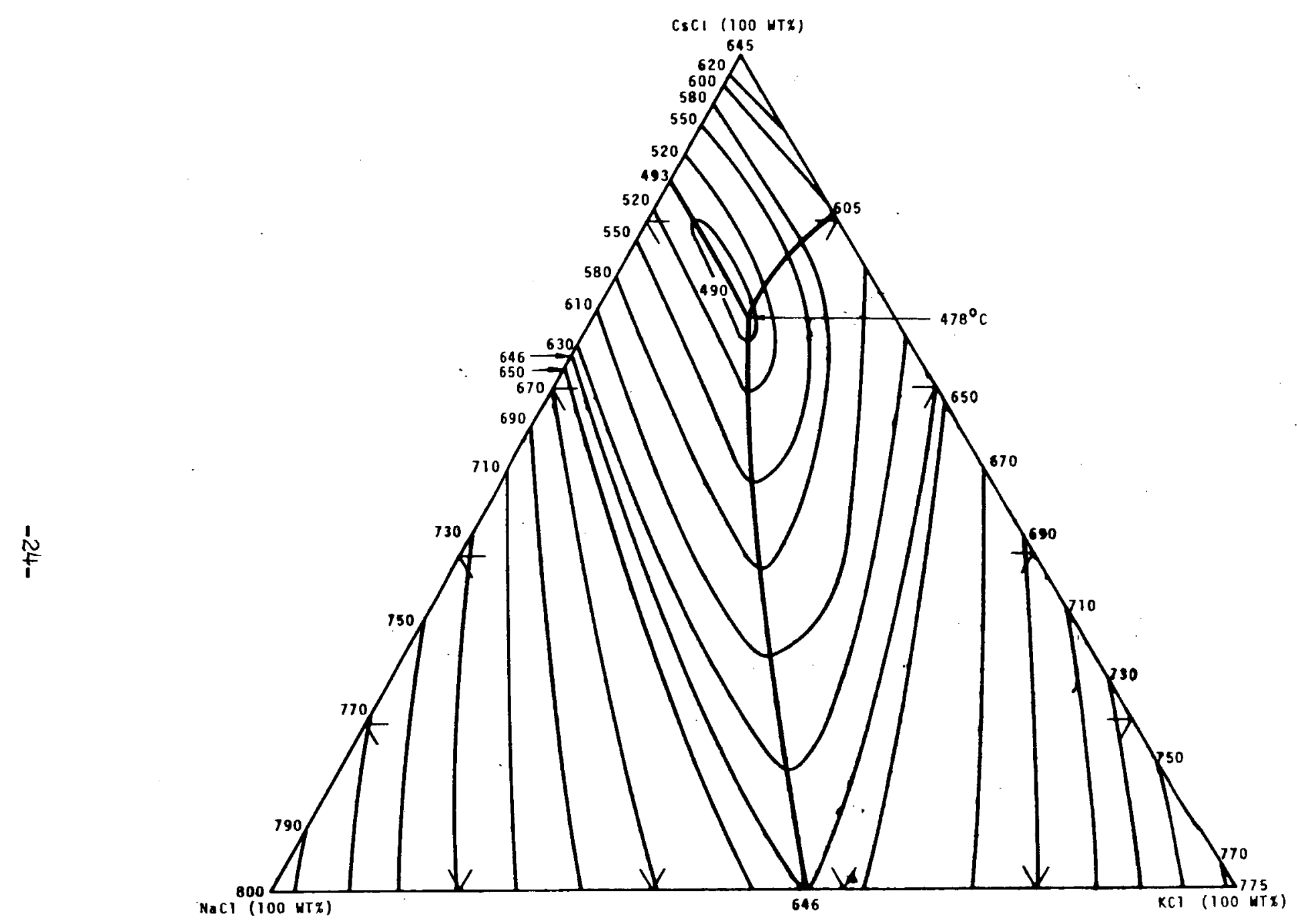

FIGURE 5 PHASE DIAGRAM FOR THE SYSTEM CsC1-KC1-NaCl (Composition in wt\%) 


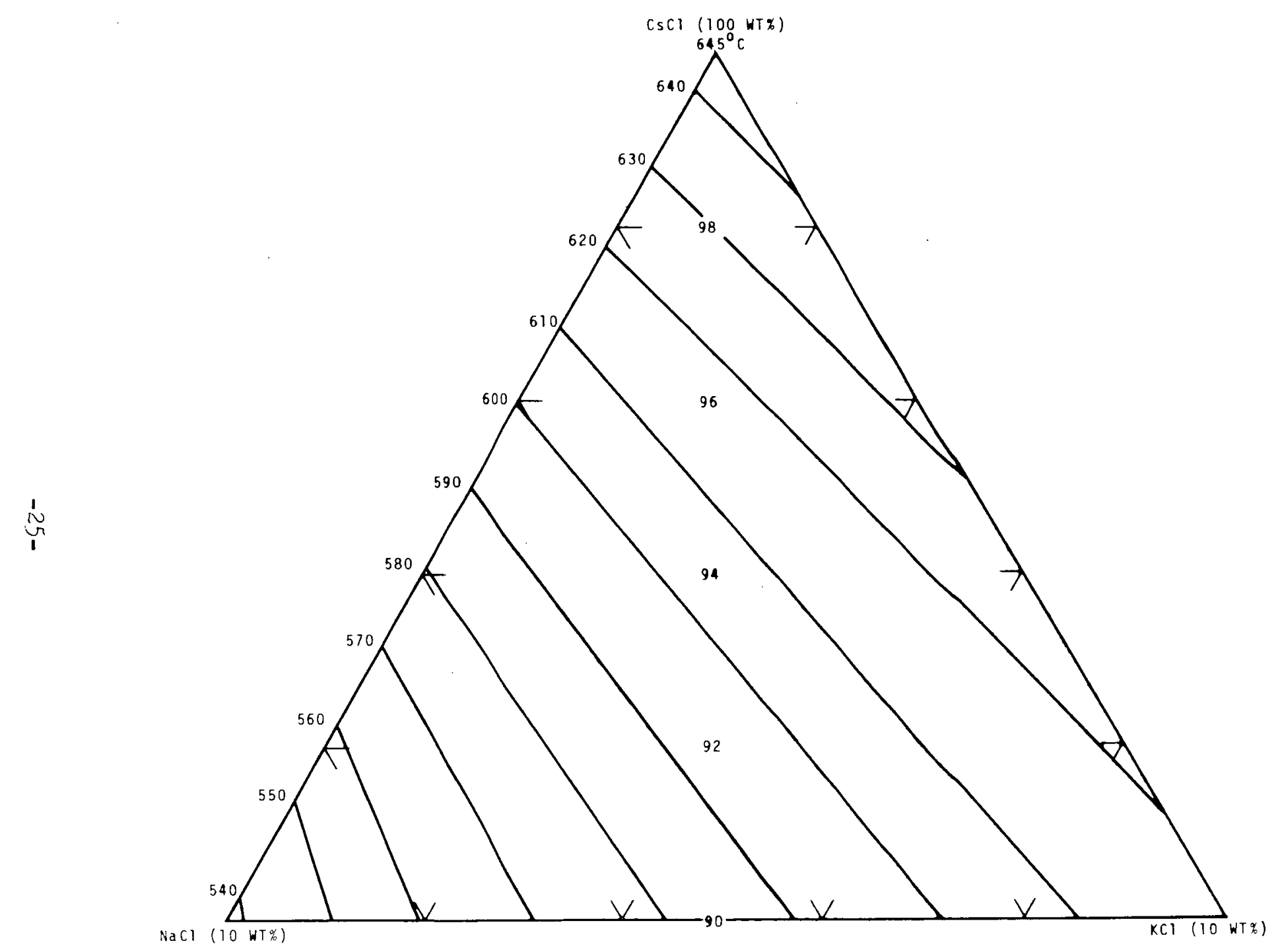

FIGURE 6 PHASE DIAGRAM FOR THE SYSTEM CsC1-KC1-NaCl (Composition in wt\%) 


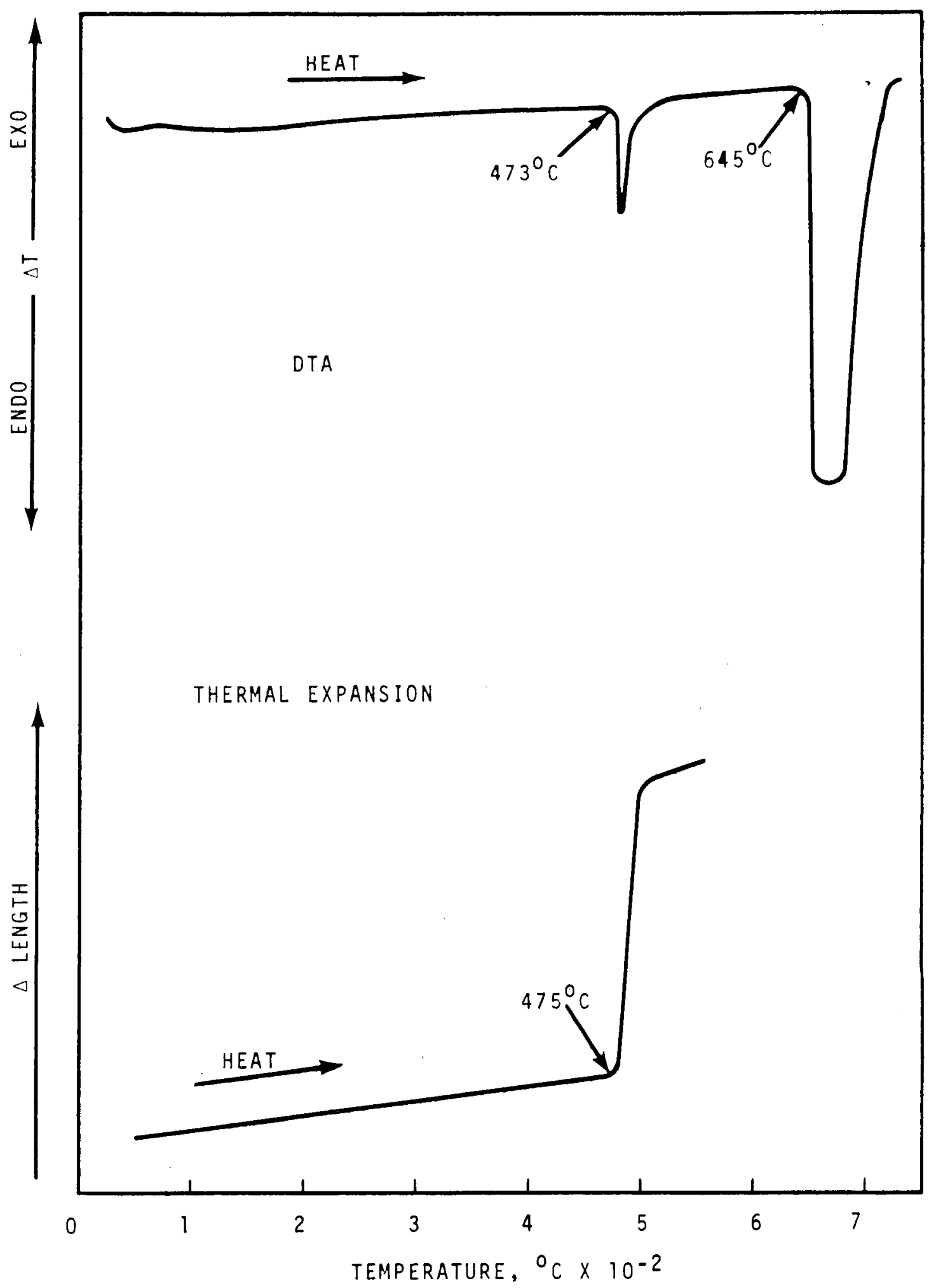

FIGURE 7 THERMAL EXPAINSION AND DTA CURVES FOR PURE CESIUM CHLORIDE ON HEATING 


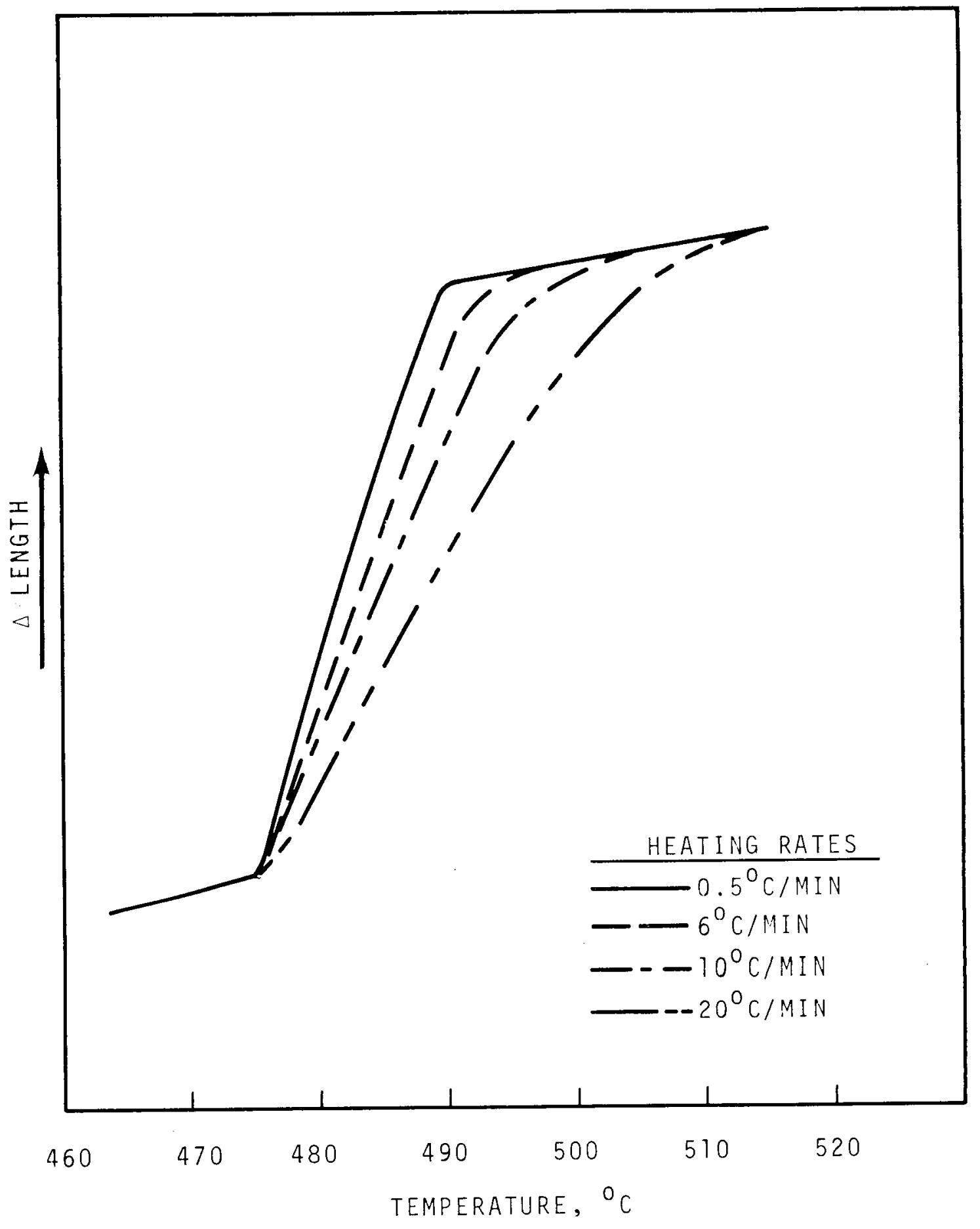

FIGURE 8 THE EFFECT OF HEATING RATE ON CSCl PHASE TRANSITION AS DETERMINED BY THERMAL EXPANSION MEASUREMENTS 


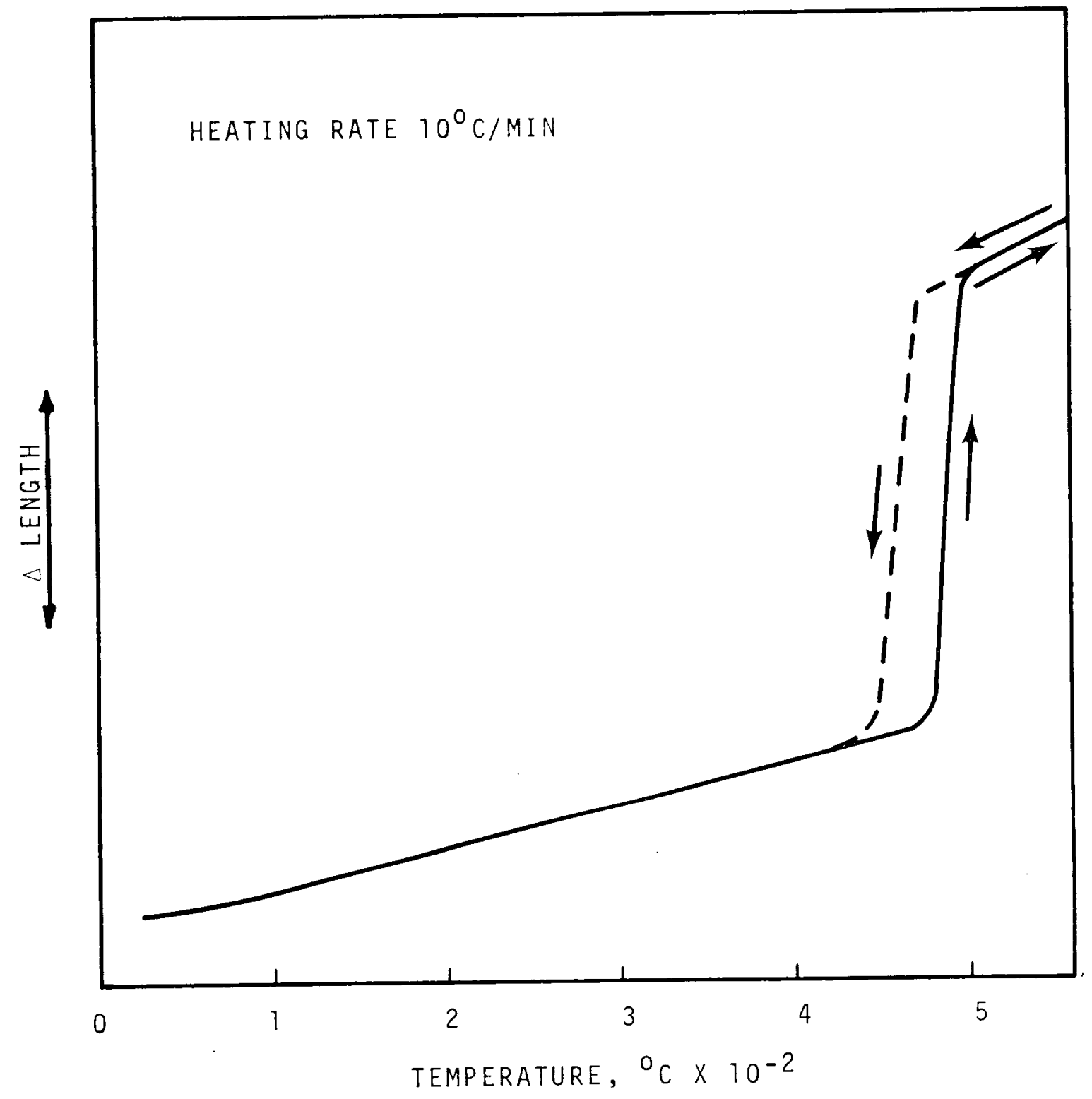

FIGURE 9 THERMAL EXPANSION AND CONTRACTION OF CsC1 ON HEATING AND COOLING $-23-$ 


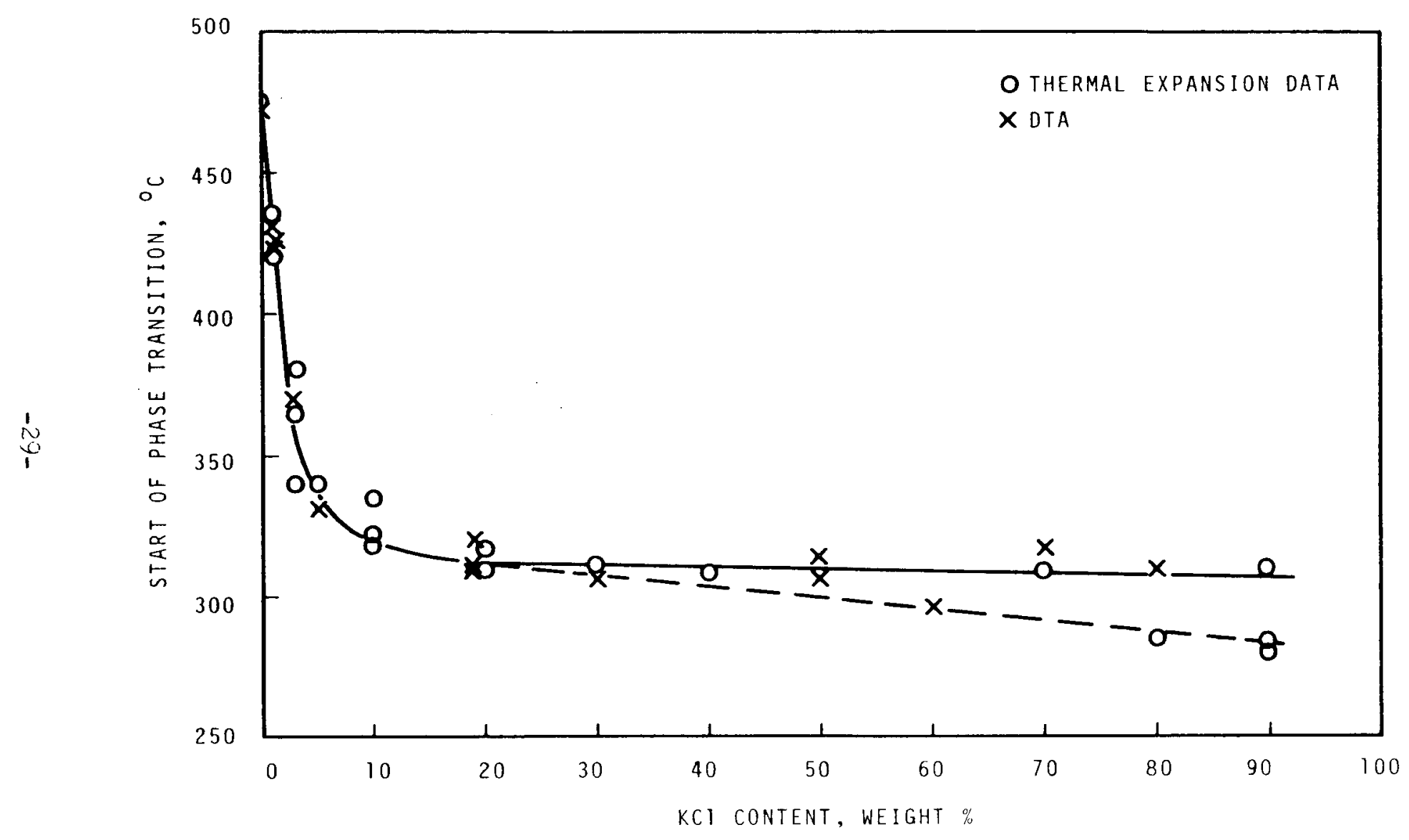

FIGURE 10 START OF PHASE TRANSITION FOR CSCl-KC1 BINARY AS A FUNCTION OF KCI CONTENT 


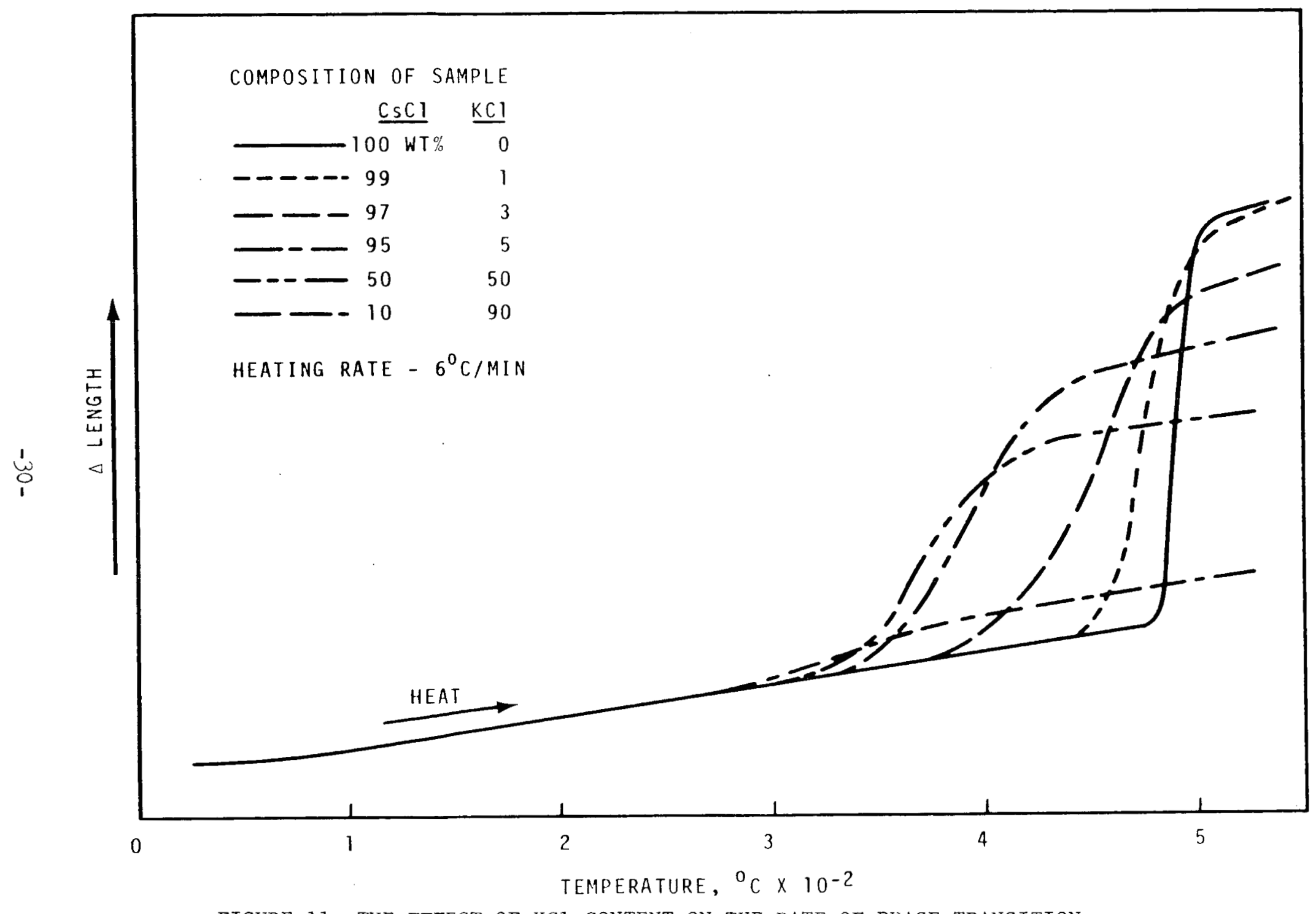

FIGURE 11 THE EFFECT OF KC1 CONTENT ON THE RATE OF PHASE TRANSITION 

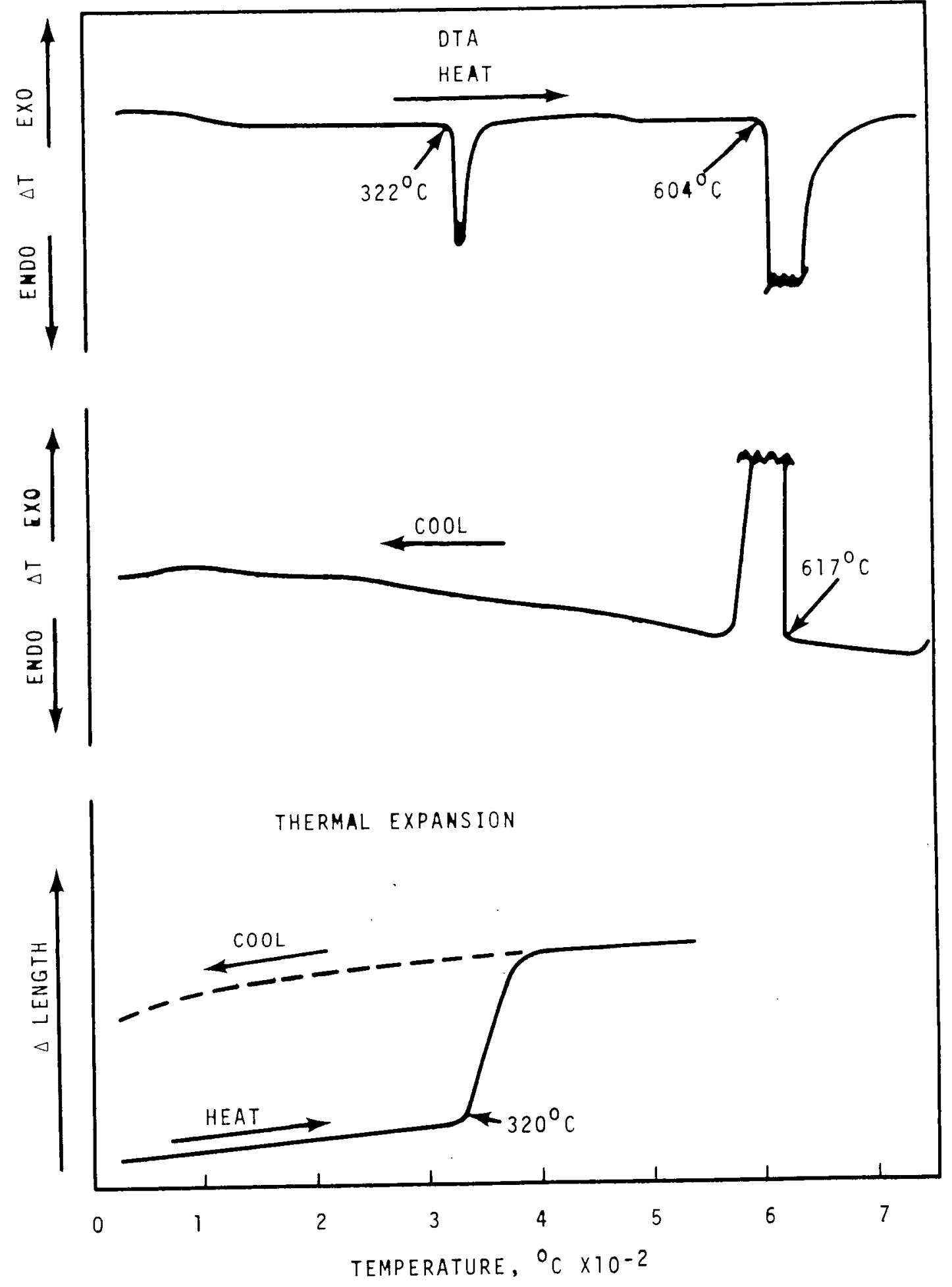

FIGURE 12 DTA AND THERMAL EXPANSION MEASUREMENTS FOR ANNEALED CsC1-10 wt\% KC1 SAMPLES

$$
-31-
$$




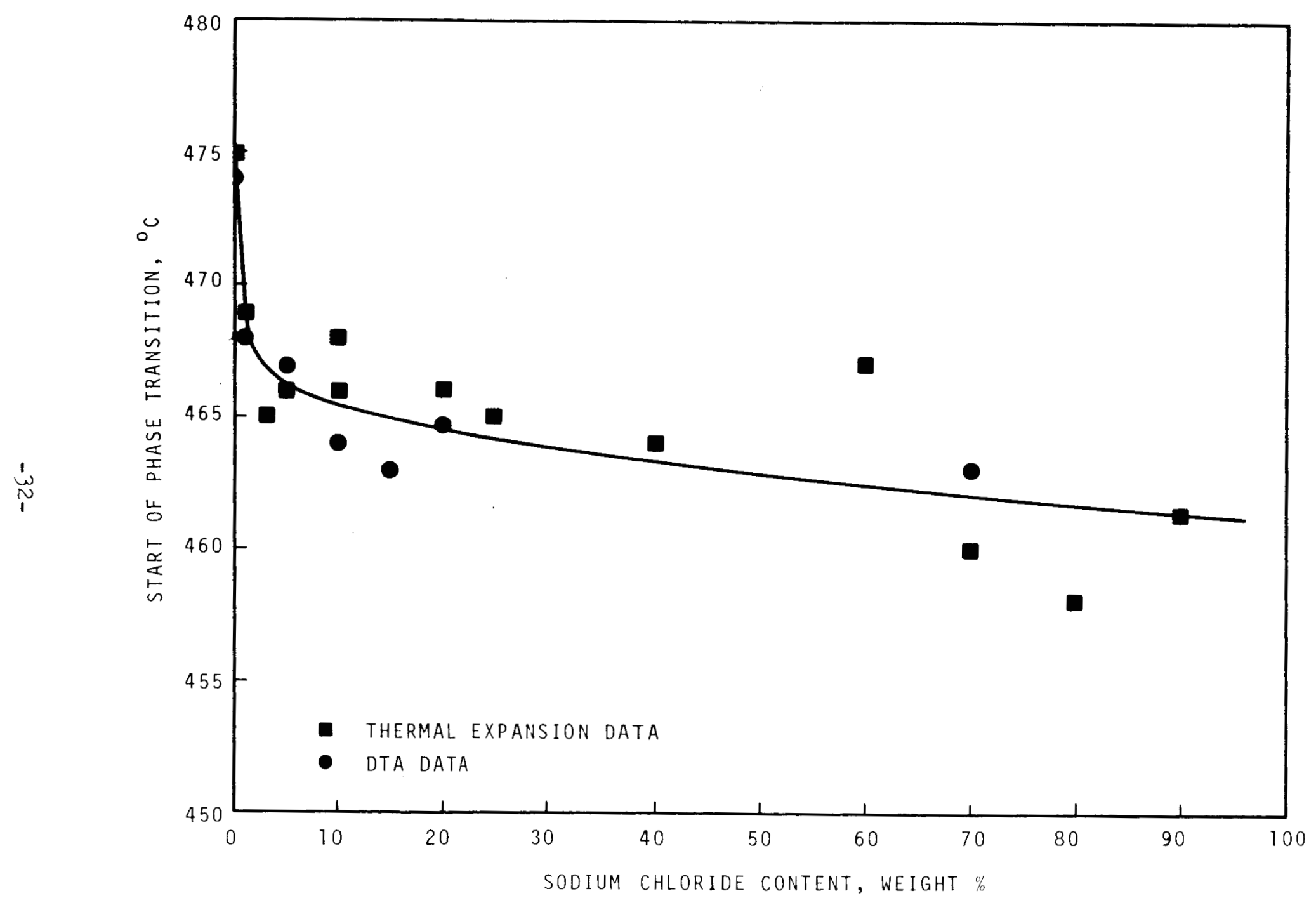

FIGURE 13 THE EFFECT OF NaC1 CONTENT ON THE PHASE TRANSITION TEMPERATURE OF THE CSC1-NaC1 SYSTEM 


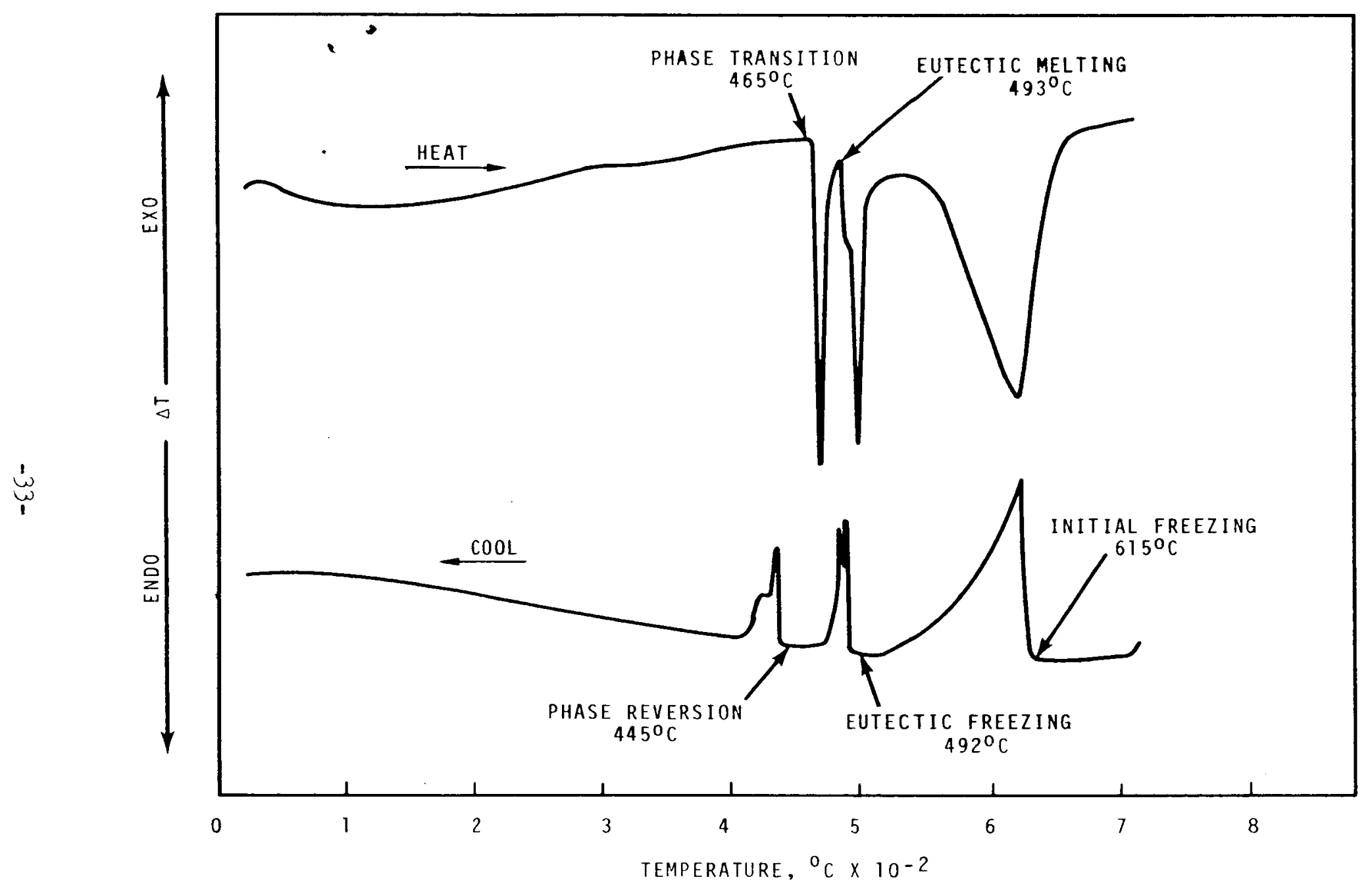

FIGURE 14 DIFFERENTIAL THERMAL ANALYSIS OF A CsC1-3 wt\% NaC1 SAMPLE 


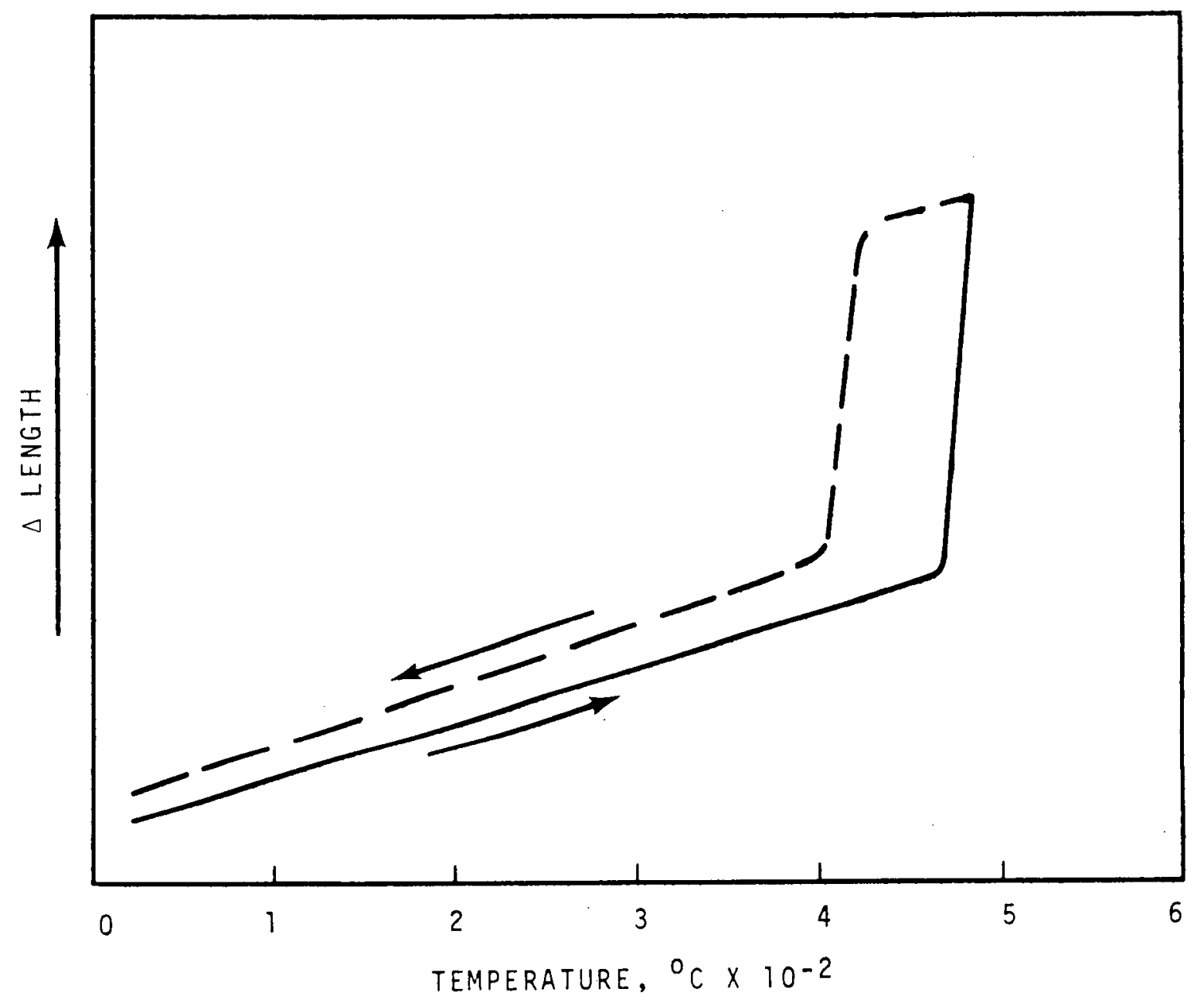

FIGURE 15 THERMAL EXPANSION OF A CsC1-10 wt\% NaC1 SAMPLE $-34-$ 


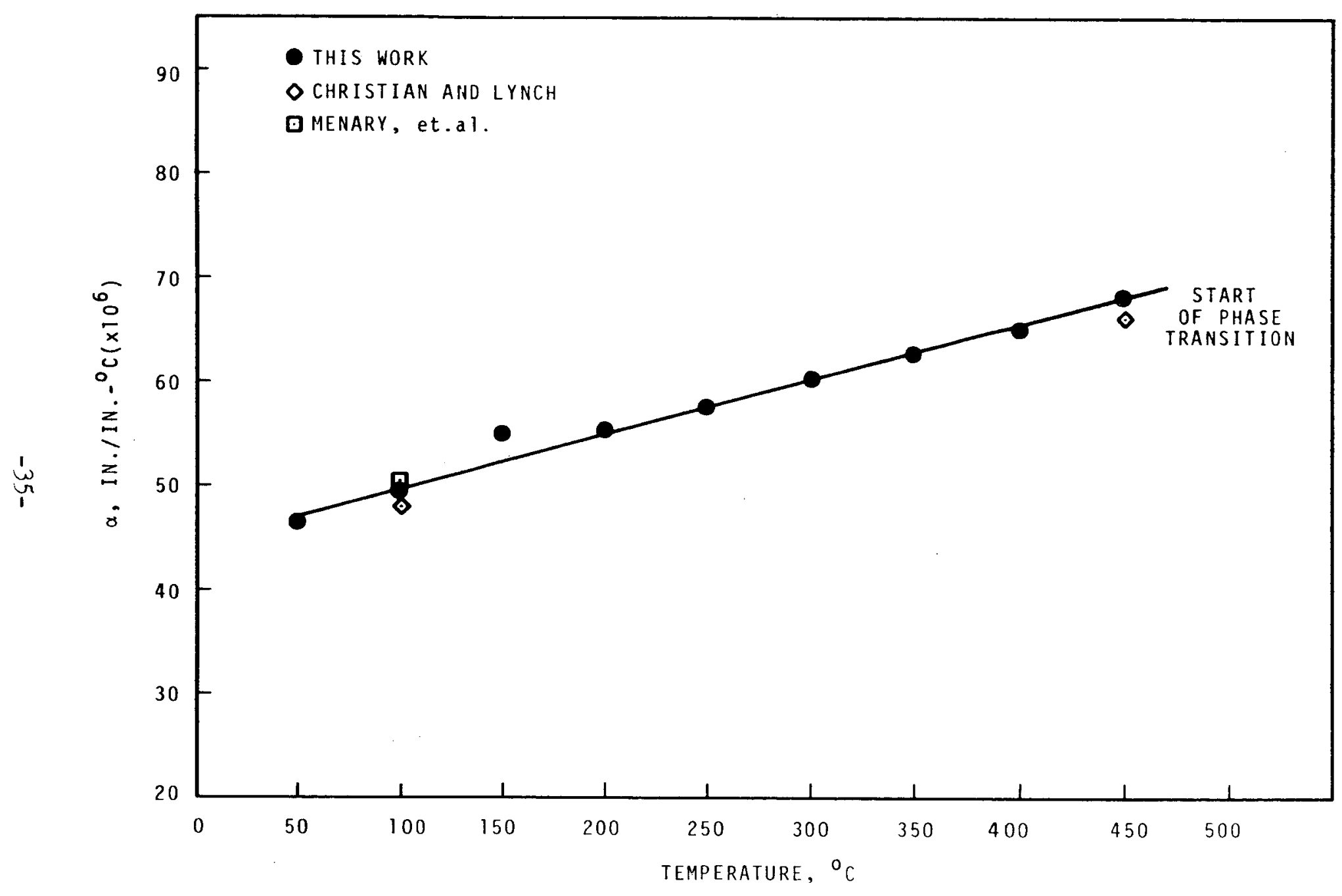

FIGURE 16 THERMAL EXPANSION COEFFICIENT FOR CSC1 AS A FUNCTION OF TEMPERATURE 


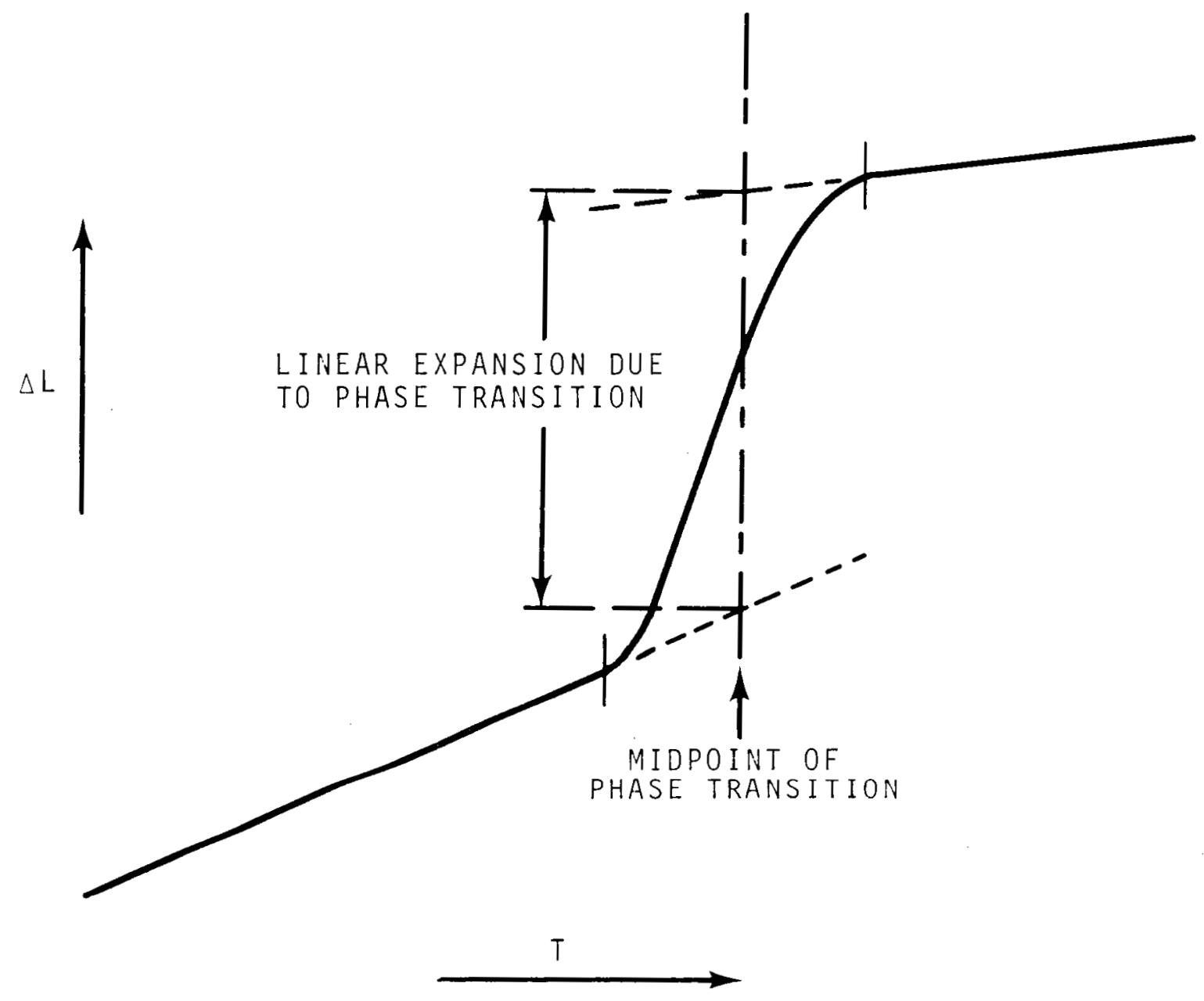

FIGURE 17 DETERMINATION OF LINEAR EXPANSION AT THE PHASE TRANSITION $-36-$ 


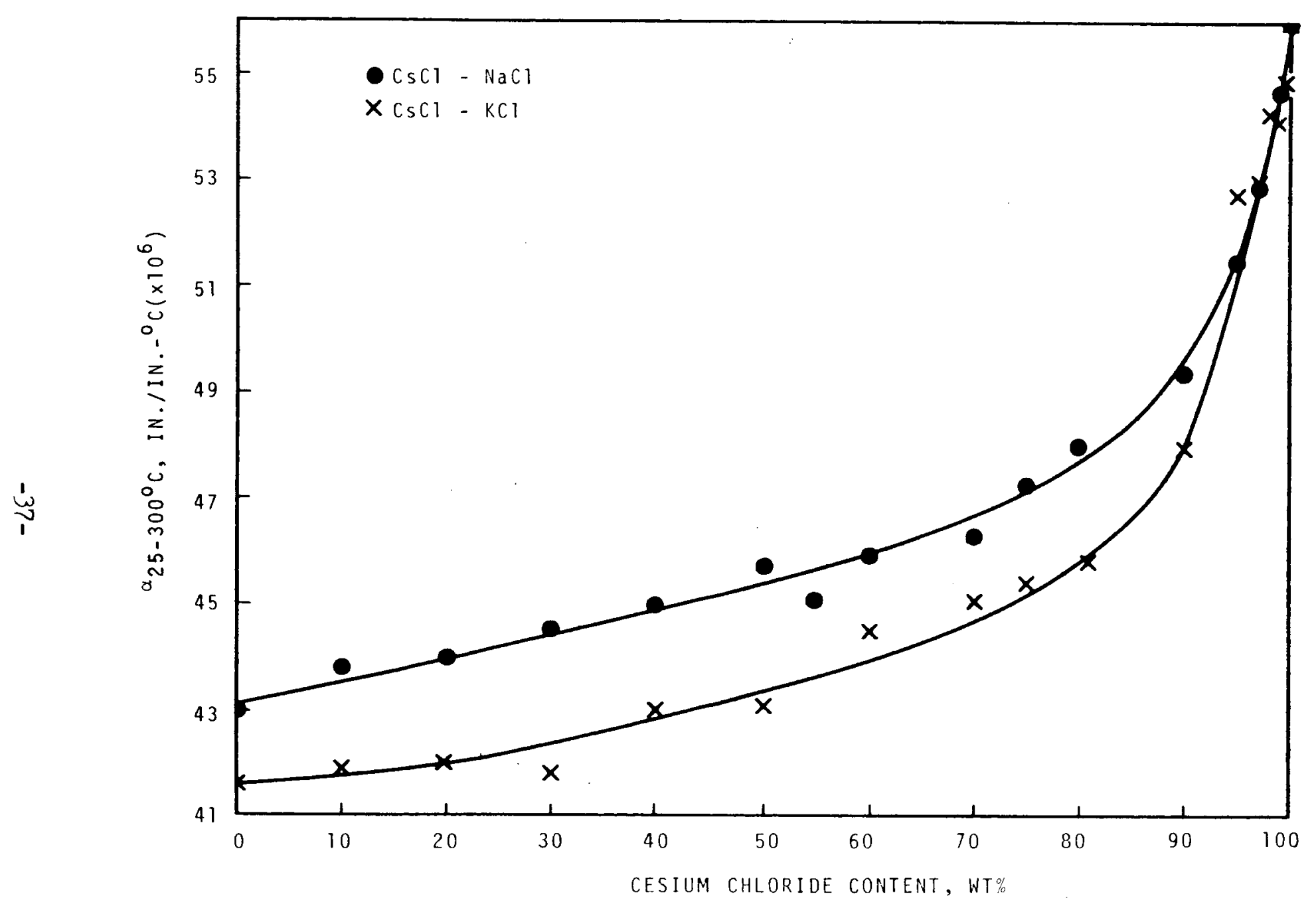

FIGURE 18 THE EFFECT OF COMPOSITION ON THE AVERAGE THERMAL EXPANSION COEFFICIENT BETWEEN $25-300^{\circ} \mathrm{C}$ FOR THE SYSTEMS CsCl-KC1 AND CsC1-NaCl 


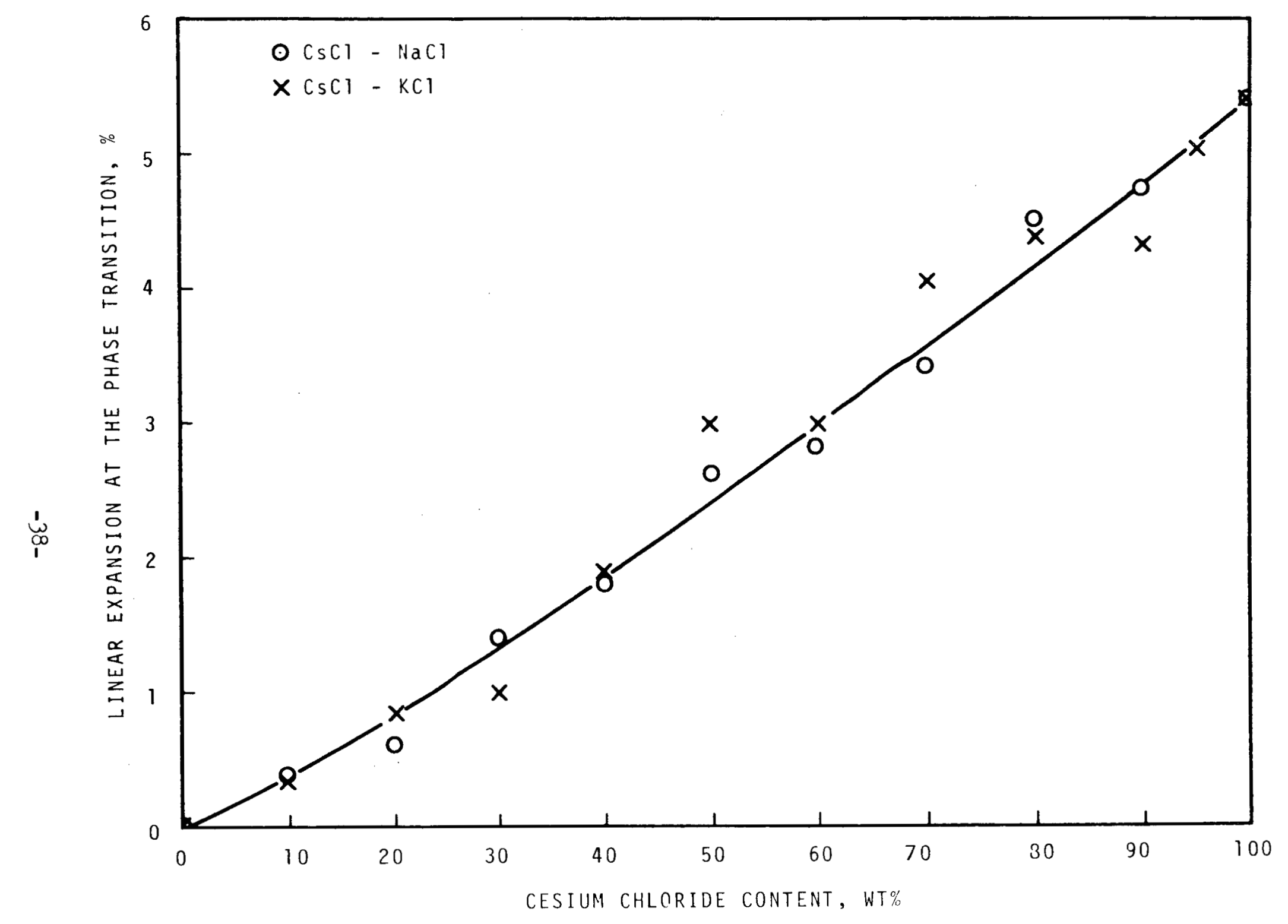

FIGURE 19 CHANGE IN LINEAR EXPANSION AT THE PHASE TRANSITION WITH CsC1 CONTENT FOR THE SYSTEMS CsC1-KCl and CsC1-NaC1 


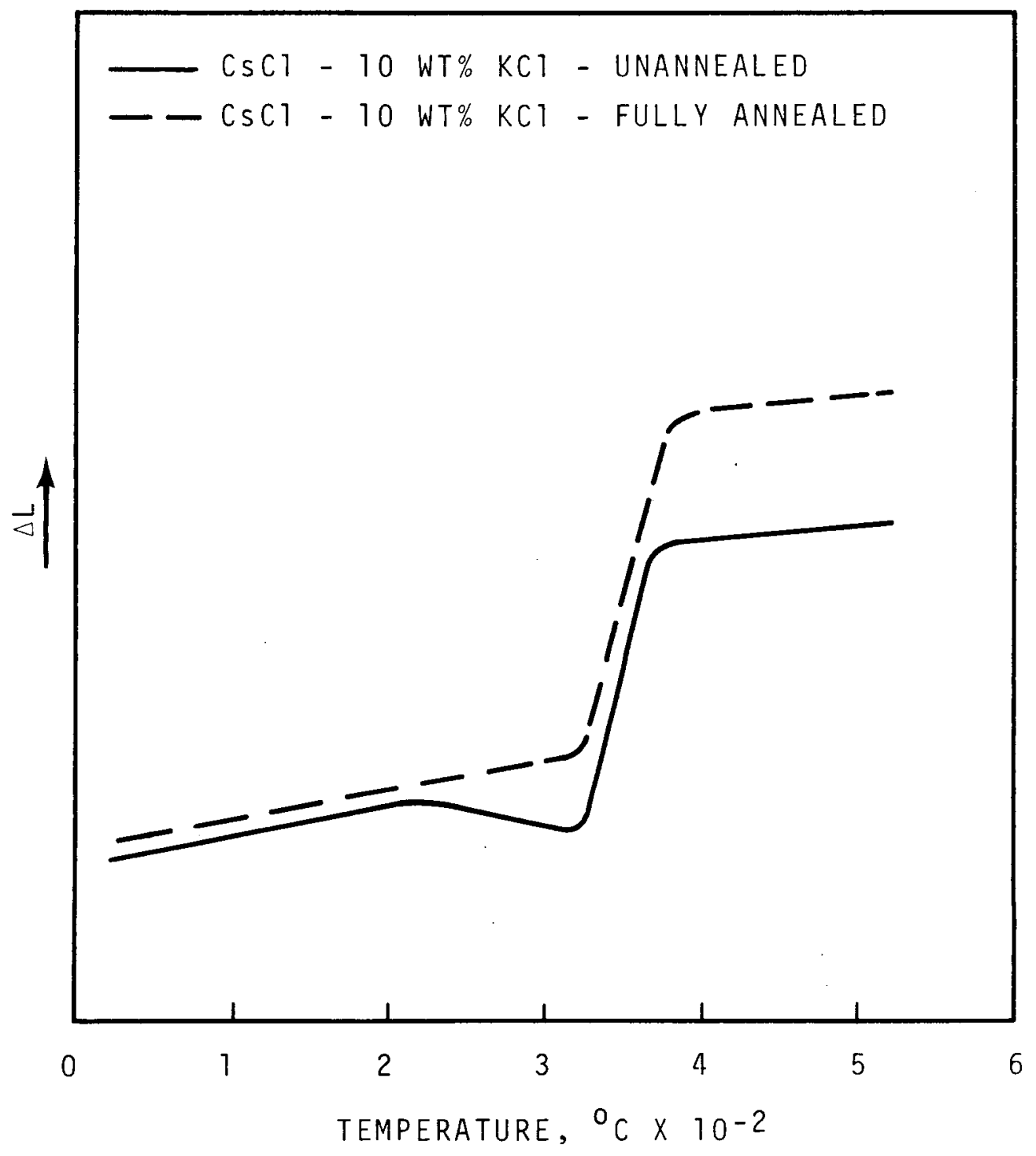

FIGURE 20 THERMAL EXPANSION CURVES

FOR ANNEALED AND UNANNEALED CsC1-10 wt\% KCI SAMPLES

$-39-$ 


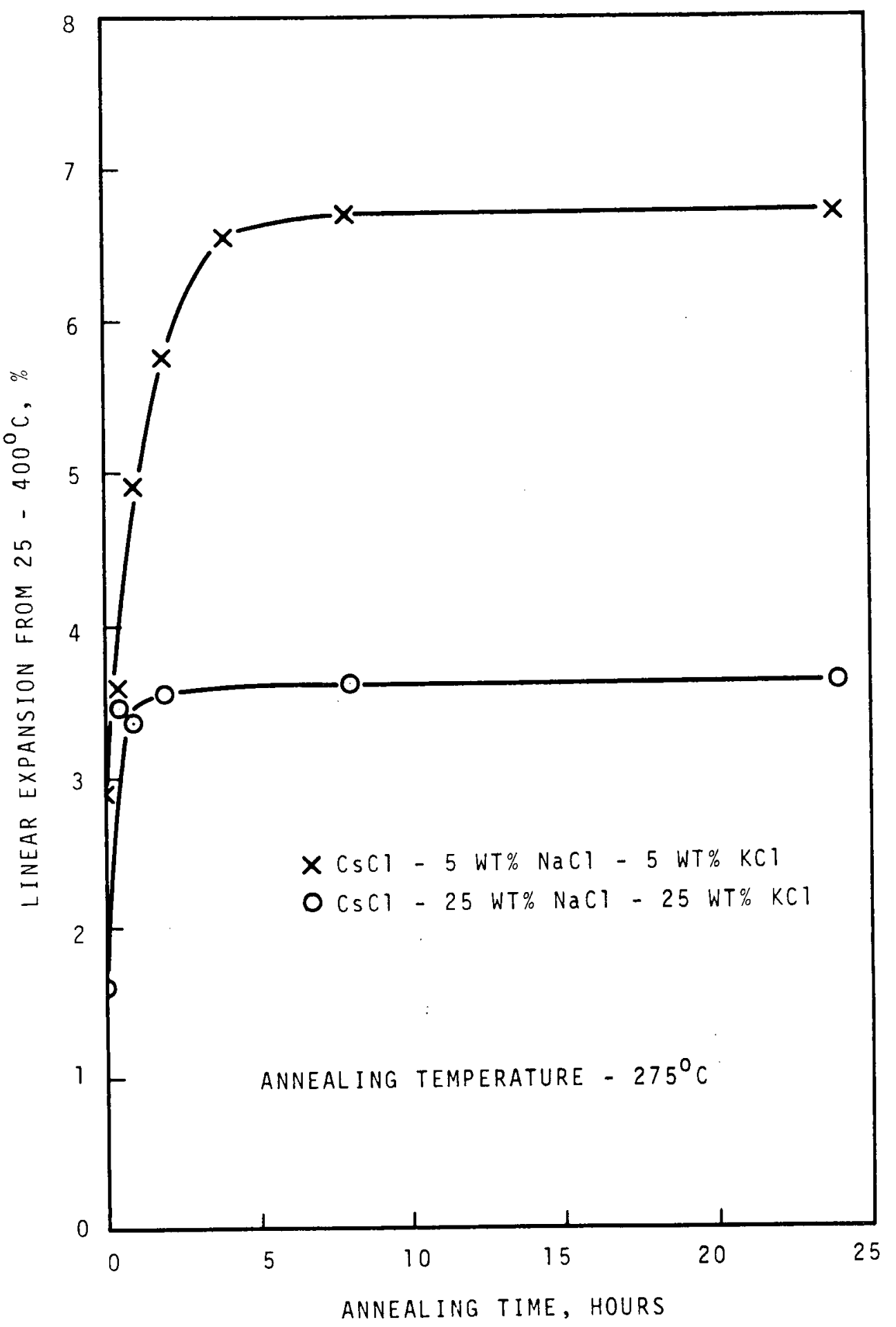

FIGURE 21 THE EFFECT OF ANNEALING TIME ON THE LINEAR EXPANSION OF CSCl-NaCl-KC1 SAMPLES $-40-$ 


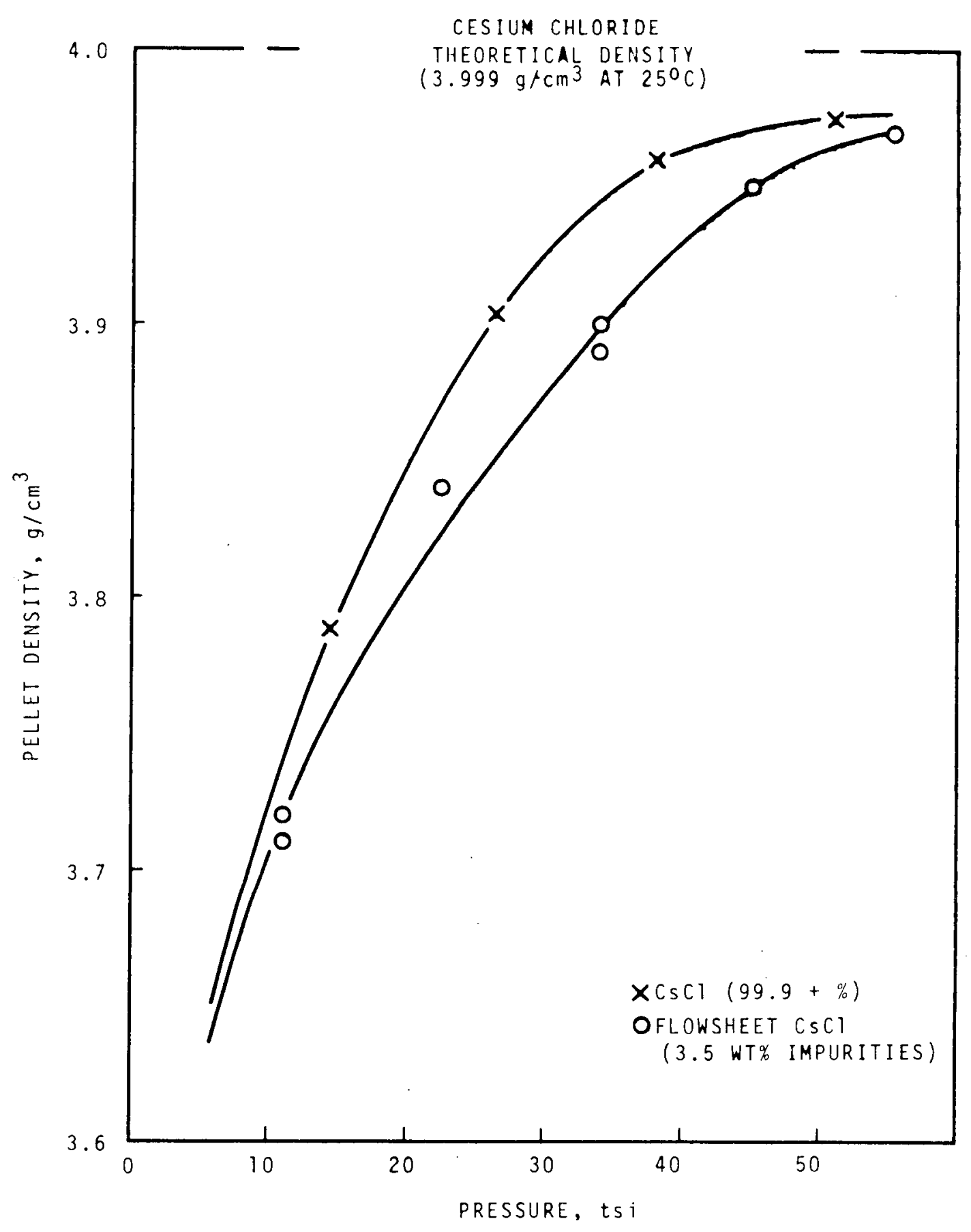

FIGURE 22 COMPACTION OF CsCl BY COLD PRESSING -41 - 


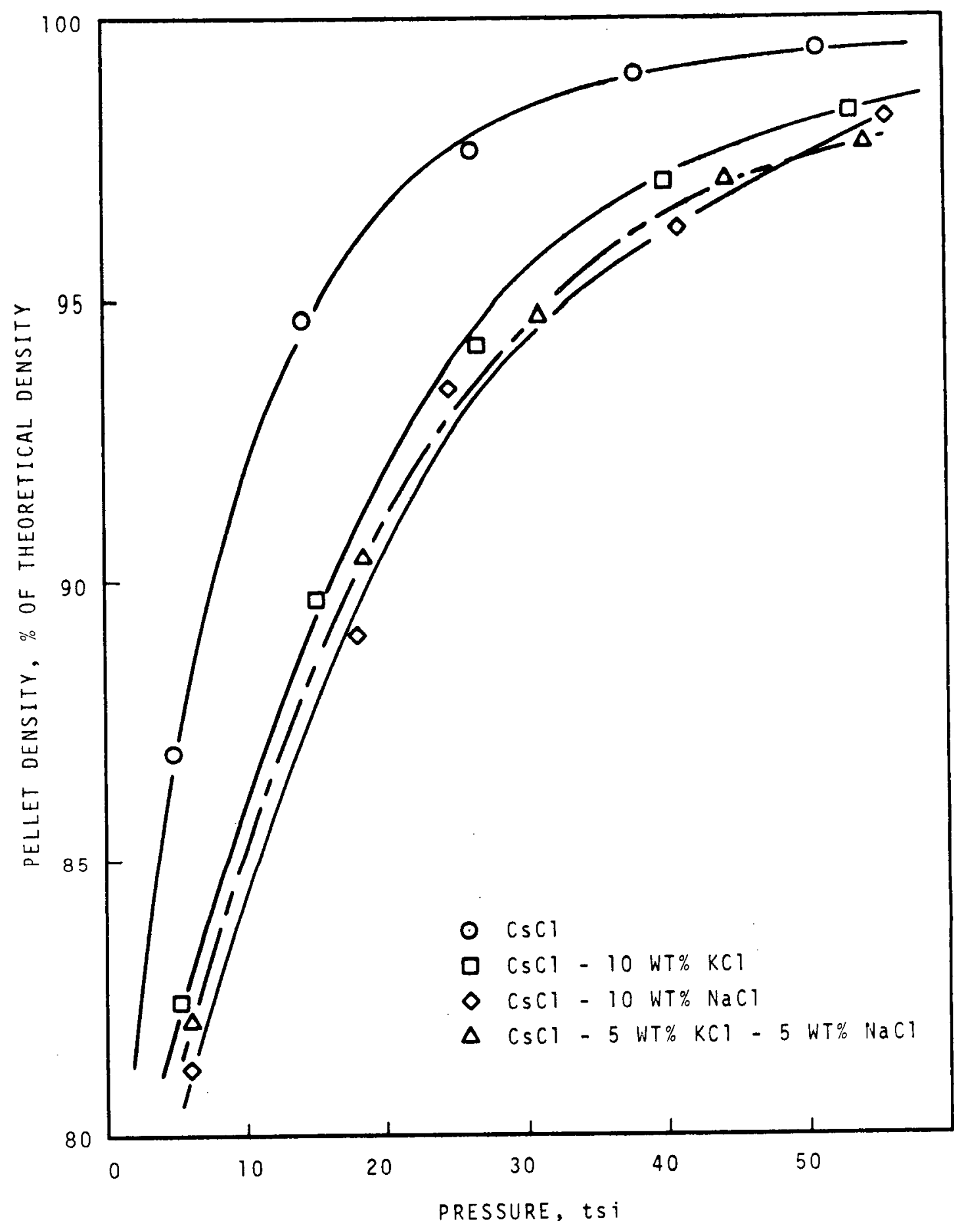

FIGURE 23 COLD PRESSING OF ALKALI CHLORIDE MIXTURES -42- 


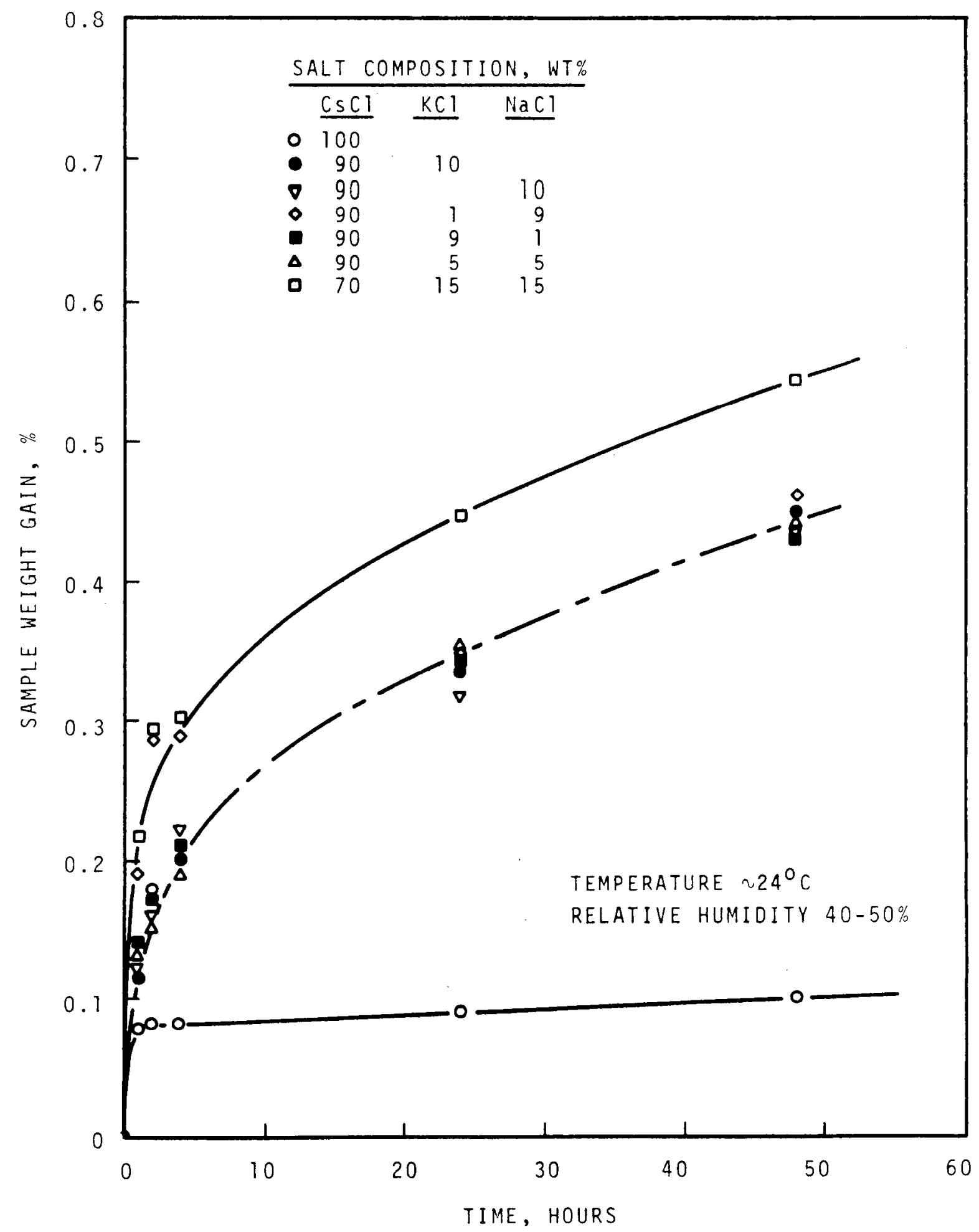

FIGURE 24 ADSORPTION OF WATER BY CSCI AND ALKALI CHLORIDE MIXTURES $-43-$ 